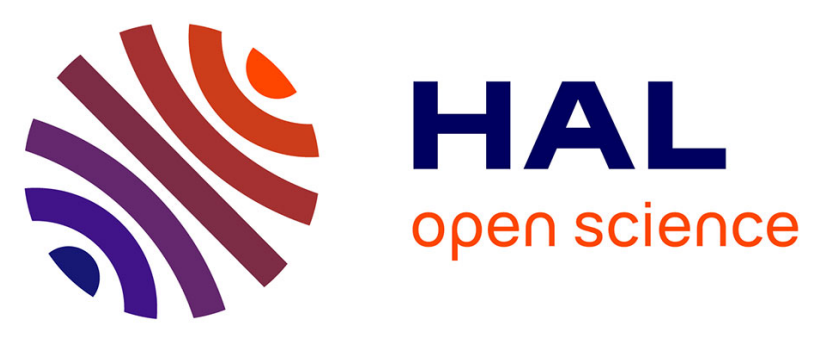

\title{
Haptic-2D: A new haptic test battery assessing the tactual abilities of sighted and visually impaired children and adolescents with two-dimensional raised materials
}

Anaïs Mazella, Jean-Michel Albaret, Delphine Picard

\section{- To cite this version:}

Anaïs Mazella, Jean-Michel Albaret, Delphine Picard. Haptic-2D: A new haptic test battery assessing the tactual abilities of sighted and visually impaired children and adolescents with twodimensional raised materials. Research in Developmental Disabilities, 2016, 48, pp.103 - 123. 10.1016/j.ridd.2015.10.012 . hal-01464658

\author{
HAL Id: hal-01464658 \\ https://hal.science/hal-01464658
}

Submitted on 2 May 2018

HAL is a multi-disciplinary open access archive for the deposit and dissemination of scientific research documents, whether they are published or not. The documents may come from teaching and research institutions in France or abroad, or from public or private research centers.
L'archive ouverte pluridisciplinaire HAL, est destinée au dépôt et à la diffusion de documents scientifiques de niveau recherche, publiés ou non, émanant des établissements d'enseignement et de recherche français ou étrangers, des laboratoires publics ou privés. 
Haptic-2D: A new haptic test battery assessing the tactual abilities of sighted and visually impaired children and adolescents with two-dimensional raised materials

Anaïs Mazella ${ }^{\mathrm{a}, \mathrm{b}}$, Jean-Michel Albaret $^{\mathrm{b}} \&$ Delphine Picard ${ }^{\mathrm{a}^{*}}$

${ }^{a}$ Aix Marseille University, PSYCLE EA3273, 13621 Aix en Provence, France

${ }^{\mathrm{b}}$ University of Toulouse III, PRISSMH EA4561, 31062 Toulouse, France

* Corresponding author

Prof. Delphine Picard

Aix Marseille Université

Maison de la Recherche

Centre PsyCLE EA3273

29 avenue Schuman

13621 Aix en Provence

France

E-mail: delphine.picard@univ-amu.fr

Tel.: + 33413553756 
Haptic-2D: A new haptic test battery assessing the tactual abilities of sighted and visually impaired children and adolescents with two-dimensional raised materials

\begin{abstract}
To fill an important gap in the psychometric assessment of children and adolescents with impaired vision, we designed a new battery of haptic tests, called Haptic-2D, for visually impaired and sighted individuals aged five to 18 years. Unlike existing batteries, ours uses only two-dimensional raised materials that participants explore using active touch. It is composed of 11 haptic tests, measuring scanning skills, tactile discrimination skills, spatial comprehension skills, short-term tactile memory, and comprehension of tactile pictures. We administered this battery to 138 participants, half of whom were sighted $(n=69)$, and half visually impaired (blind, $n=16$; low vision, $n=53$ ). Results indicated a significant main effect of age on haptic scores, but no main effect of vision or Age x Vision interaction effect. Reliability of test items was satisfactory (Cronbach's alpha, $\alpha=0.51-0.84$ ). Convergent validity was good, as shown by a significant correlation (age partialled out) between total haptic scores and scores on the B101 test $\left(r_{p}=0.51, n=47\right)$. Discriminant validity was also satisfactory, as attested by a lower but still significant partial correlation between total haptic scores and the raw score on the verbal WISC $\left(r_{p}=0.43, n=62\right)$. Finally, test-retest reliability was good ( $r_{\mathrm{s}}=0.93, n=12$; interval of one to two months). This new psychometric tool should prove useful to practitioners working with young people with impaired vision.
\end{abstract}

Keywords: haptic; psychometric assessment; children; visual impairment 


\section{Introduction}

The psychometric assessment of children and adolescents with impaired vision (i.e., those who are totally blind, legally blind or have low vision) is still challenging, inasmuch as most available instruments rely heavily on sight or were originally designed for sighted participants. The usability of such instruments in persons with impaired vision is therefore subject to debate (Reid, 1995, 2002). Evidence of major dissatisfaction among professionals with current assessment procedures of cognitive abilities in visually impaired persons has been provided by several American surveys (Bauman \& Kropf, 1979; Hannan, 2007; Miller \& Skillman, 2003). Today, psychologists mostly use the verbal subscale of the Wechsler Intelligence Scale for Children-Revised (WISC-IV-R; Wechsler, 2005) to assess the cognitive functioning of visually impaired children (see Atkins, 2011). However, as its name implies, this verbal subscale does not yield any information about nonverbal reasoning. Furthermore, doubts have been expressed about the appropriatness of using some verbal items with visually impaired children, who may be at a disadvantage (and therefore obtain lower scores) compared with their sighted peers (Tillman, 1967). Psychologists also use handmade tests (e.g., producing their own tactile versions of existing tests, enlarging characters or increasing constrasts in existing tests), but such tests lack scientific grounding. Thus, psychologists and educationalists working with young people who have a visual disability currently lack efficient assessment instruments. One way of filling this gap would be to develop nonvisual tests that are specifically designed and standardized for visually impaired children.

The haptic modality (i.e., sense of active touch; Gibson, 1966; Revesz, 1950) represents an interesting alternative modality to vision for assessing the perceptual-motor and cognitive functioning of children with impaired vision. This modality plays a key role in the development of blind children (Hatwell, 2003; Withagen, Verloed, Janssen, Knoors, \& Verhoeven, 2010). The sense of haptics is particularly effective at processing the material properties of three-dimensional (3D) objects (e.g., texture, hardness, and temperature) and, to a lesser extent, their geometric properties (e.g., shape, size, or volume; Hatwell, Streri, \& Gentaz, 2003; Klatzky, Lederman, \& Metzger, 1985; Lederman \& Klatzky, 2009). The sense of haptics can also be used to process two-dimensional (2D) objects, such as the raised dots in braille patterns (see Millar, 1997), and the variety of raised-line materials (e.g., geometric shapes, diagrams, graphs, maps, plans, patterns, and outline drawings) that visually impaired children encounter at school or at home in the course of their education. However, owing to 
the sequential nature of manual haptic exploration, the processing of 2D objects' spatial information is slow and places heavy demands on memory and spatiotemporal integration. As a result, the haptic processing of $2 \mathrm{D}$ objects is usually far less effective than that of $3 \mathrm{D}$ objects. For example, Klatzky, Loomis, Lederman, Wake, and Fujita (1993) showed that the haptic identification of real objects was clearly superior to that of raised 2D depictions: in their study, blindfolded adults were very fast $(\approx 1-2 \mathrm{sec})$ and accurate (nearly $100 \%)$ at identifying common objects by hand (like a comb or an ashtray), whereas they were slower $(\approx$ $90 \mathrm{sec})$ and far less accurate $(<30 \%)$ at identifying by touch the raised-line drawings of these objects. Despite extensive fundamental research on haptic perception (Klatzky \& Lederman, 2009; Lederman \& Klatzky, 2009), both applied (psychometric) and developmental studies of haptic functioning in children who are visually impaired remain rare.

A recent literature review of haptic psychometric tests (i.e., tests performed in the haptic modality with no reliance on vision; Mazella, Albaret, \& Picard, 2014a) showed that most tests assess adult participants, rather than children. Moreover, these tests are confined to interactions with $3 \mathrm{D}$ objects, as opposed to $2 \mathrm{D}$ materials. Two categories of tests were identified: tests where active touch is used as a replacement for vision (haptic analogs of mainstream tests such as the Cognitive Test for the Blind (CTB), an analog of the Wechsler Intelligence Scale for Adults; Dial, Mezger, Gray, Massey, Chan, \& Hull, 1990), and tests where active touch is used per se to assess haptic functioning (specialist tests such as the Haptic Sensory Discrimination Test; Dial et al., 1990). Regardless of their category, most of the reviewed tests lacked comprehensive psychometric indices of sensitivity, reliability, and validity. The authors of this review therefore called for the design of new haptic tests incorporating all the properties expected of genuine psychometric tests, and more specifically for the design of developmental haptic test batteries.

To date, two notable psychometric studies of haptic functioning in children who are visually impaired have been conducted from a developmental perspective. The first study was a research project carried out in the Netherlands by Withagen and colleagues (Withagen, Baerwaldt, Blok, Ekkens, Hamelink, \& Vervloed, 2005; Withagen \& Schellingerhout, 2004; see also Withagen, Vervloed, Janssen, Knoors, \& Verhoeven, 2009). These authors developed and validated a psychometric instrument called the Tactual Profile, which assessed the tactual functioning of blind children from ages one to 15. The Tactual Profile consisted of a large set of items (430) measuring the tactual skills required from blind children to perform everyday 
and school-related activities. The items were arranged according to age level and domain of tactual functioning (sensory, motor, perceptual, and practical). Tactual sensory functioning items (106) assessed passive perception (e.g., tactual awareness, touch sensitivity). Tactual motor functioning items (52) assessed motor proficiency (e.g., tactual exploration, manipulation). Tactual perceptual functioning items (162) assessed the interpretation of tactual information (e.g., perception of detail, discrimination). Finally, practical skills items (110) probed daily life skills involving touch (e.g., touch strategy, linking function to object). This instrument only used 3D materials, and was validated with an original sample of 55 participants. It had both convergent (assessment of intelligence and haptic perception in blind children; Mommers, 1974) and discriminant (verbal subscale of WISC-IV-R) validity, and satisfactory test-retest reliability $(r=0.94)$. Special educationalists working with blind children rated the Tactual Profile as an important and useful instrument, notably because it gave them useful leads for future interventions. However, one major drawback of this instrument was its length (administration time commonly totalled 4-5 hours with children over 6 years).

The second study was a research project conducted in Spain by Ballesteros and colleagues (Ballesteros \& Bardisa, 2002; Ballesteros, Bardisa, Millar, \& Reales, 2005; Ballesteros, Bardisa, Reales, \& Muniz, 2005). These authors developed a psychometric instrument called the Haptic Battery, which assessed the development of the perceptual and cognitive abilities involved in haptic processing by visually impaired children (and sighted controls) from age three to 16. The Haptic Battery consisted of 14 subtests measuring spatial comprehension (seven subtests), short-term memory (three subtests), object identification (one subtest), raised-shape identification (one subtest), sequential scanning (one subtest), and longer-term coding for new objects (one subtest). This instrument used both 3D and 2D materials, and was validated with an original sample of 119 participants (59 visually impaired, 60 sighted). It had satisfactory internal consistency (Cronbach's alpha, $\alpha$ 0.54-0.88), construct validity (six-factor structure), and age sensitivity. The Haptic Battery took less than an hour to administer. The authors wrote that the Haptic Battery "should prove to be a very useful, as well as valid and reliable instrument" (Ballesteros et al., 2005, p. 23). To the best of our knowledge, however, the research project was not taken any further, meaning that this promising instrument's additional psychometric properties (i.e., convergent and discriminant validity, test-retest reliability) were never measured. 
To summarize, there is still an important gap in the psychometric assessment of children and adolescents with impaired vision, which calls for further applied research using the sense of active touch (see also Theurel \& Gentaz, 2014). Following on from where Ballesteros and Withagen left off, we undertook a research project in France to develop and validate a new haptic test battery. The resulting battery, named the Haptic-2D, uses $2 \mathrm{D}$ raised materials to assess the development of tactual abilities in sighted and visually impaired children and adolescents aged five to 18 . Unlike previous applied studies, we were interested in measuring children's abilities to deal solely with 2D raised materials, as opposed to either 3D objects (e.g., Withagen et al., 2005) or a mixture of 3D and 2D tactile materials (e.g., Ballesteros et al., 2005). We focused on 2D materials because the development of tactual skills to deal with such materials is crucial for the daily activities and education of visually impaired children, but has never yet been the focus of a psychometric assessment.

Indeed, as children grow older they develop tactual skills to process efficiently a variety of increasingly complex 2D raised materials or tactile graphics at school or at home. As reported by professionals (psychologists, educators), some blind children have difficulties making sense of 2D raised displays (e.g., reading properly line diagrams during a mathematic lesson), and the roots of their problem are unclear to the extent that several components of haptic functioning may be involved (e.g., scanning difficulties where the child loses contact with the lines; spatial orientation processing difficulties where the child fails detecting changes in line orientation; or short-term memory difficulties where the child forgets the path of a line while exploring a second line). Accordingly, designing a battery of tests measuring the different components of haptic functioning with 2D raised materials would be useful to professionals working with blind children. Testing may help better understand the strengths and weaknesses of each child in processing 2D raised materials, and evaluate whether some tactual skills are at risk and should be stimulated and trained. We designed our 2D haptic battery in this perspective.

All the tests used 2D raised stimuli (dots, lines, shapes, patterns, and drawings) to assess a range of increasingly complex perceptual-motor and cognitive abilities involved in 2D haptic processing. The rationale behind selecting the tests was that efficient haptic processing of $2 \mathrm{D}$ raised materials develops concomittantly with improvements in scanning skills, discrimination skills, spatial processing skills, and short-term memorization skills. We also assumed that all these perceptual-motor and cognitive skills would be engaged in, and directly 
relevant to, the comprehension of tactile drawings, which is a complex and multi-stored activity (see, for example, Lederman, Klatzky, Chataway, \& Summers, 1990; Picard \& Lebaz, 2012). The battery included 11 haptic tests, arranged in the following five domains:

- 1. Scanning skills (two tests: dot and line scanning): They refer to basic perceptual-motor functioning with 2D raised materials. The tests assess the child's ability to detect the presence of tactile items on a page, and to follow raised lines without losing contact. Scanning skills are very fundamental to $2 \mathrm{D}$ haptic processing because the child has first to engage a series of exploratory hand movements to capture the presence of information in a raised display. Contacting all tactile items on a page is a necessary primary stage before attempting to process their properties. These tests are useful to detect possible misunderstanding of $2 \mathrm{D}$ tactile displays due to scanning difficulties (malfunctioning or incompleteness).

- 2. Tactile discrimination skills (three tests: texture, shape, and size discrimination): They refer to perceptual-motor functioning with $2 \mathrm{D}$ raised materials. The tests assess the child's ability to recognize and match tactile items according to their shape, size, and texture. Discrimination skills are crucial to efficient 2D haptic processing because tactile items in raised displays often vary with respect to their properties of shape, size and/or surface texture, and the child needs to process these properties in order to get an understanding of what is represented in a raised display. These tests are useful to detect possible misunderstanding of 2D tactile displays due to deficits in discrimination aptitudes regarding the size, shape or texture of elements.

- 3. Spatial comprehension skills (two tests: orientation and location): They refer to perceptual-motor functioning with 2D raised materials. The tests assess the child's ability to identify the spatial location and orientation of tactile items in a pattern. Spatial skills are also very important to efficient 2D haptic processing because tactile items in raised displays are spatialized, are in a specific orientation, and entertain specific inter-relation each with another. The child has to consider the spatial characteristics of raised items in order to get an accurate mental picture of a raised display. These tests are useful to detect possible misunderstanding of 2D tactile displays due to deficits in spatial comprehension.

- 4. Short-term tactile memory (two tests: dot and shape span): They refer to perceptual-motor and cognitive functioning with 2D raised materials. The tests assess the child's ability to retain a set of tactile items for a short-term period. Short-term memory skills are highly relevant to efficient 2D haptic processing because during haptic exploration of a raised display the child has to hold new information in mind for seconds during the acquisition of 
new knowledge. This capacity is limited and age-dependent (see e.g., Picard \& Monnier, 2009). Span tests are useful to identify possible deficits in short-term tactile memory.

- 5. Comprehension of tactile pictures (two tests: complete and incomplete picture identification): They refer to higher perceptual-motor and cognitive functioning with 2D raised materials. The tests assess the child's ability to identify outline drawings of familiar objects and their semantic components. The ability to identify raised-line pictures of common objects is a major aspect of 2D haptic perception and cognition, and it has been the focus of many studies (e.g., D’Angiulli, Kennedy, \& Heller, 1998; Kennedy, 1993; Lederman et al., 1990). Recent studies have shown that this ability was age-dependent (Overvliet, Wagemans, \& Krampe, 2013; Picard, Albaret, \& Mazella, 2013). Tests using tactile picture naming responses were therefore included in order to identify possible deficits in 2D haptic functioning during development.

Some of the tests we selected were taken or adapted from Ballesteros and colleagues' Haptic Battery (e.g., scanning tests and short-term memory tests). The tactile picture comprehension tests were taken from previous pilot studies demonstrating their developmental sensitivity in sighted participants (see Picard et al., 2013) and their usability with visually impaired children (see Mazella, Albaret, \& Picard, 2014b; Picard, Albaret, \& Mazella, 2014). Finally, we took care to measure all the battery's psychometric properties so that a valid and reliable instrument could be made available to practitioners working with visually impaired children and adolescents.

\section{Method}

\subsection{Participants}

A total of 138 French participants, aged 5-25 years, took part in the study. Half were visually impaired (either blind or low vision), and half were sighted controls (normal or corrected-tonormal vision). In each group, participants were divided into six age groups (for the characteristics of these groups, see Table 1). These age groups covered the periods of childhood (5-6 years; 7-8 years; 9-10 years), adolescence (11-14 years; 15-18 years), and young adulthood (18-25 years). There were 13 visually impaired and 13 sighted participants per age group, except for the additional group of young adults, which contained four visually impaired and four sighted participants. Participants from the visually impaired and sighted 
groups were matched for chronological age. Student's $t$ test for matched samples comparing visually impaired and sighted participants on mean chronological age indicated no significant between-group difference, $t=-0.72, p=0.47, n s$. There were approximately the same numbers of boys and girls in each group, with no significant between-group difference in terms of sex distribution, as revealed by a $2 \times 2$ chi-square test, $\chi^{2}(N=138)=1.05, p=0.30$, ns. Manual preference was determined using two items (hand used for drawing and hand used for throwing a ball) taken from the Edinburgh Handedness Questionnaire (Oldfield, 1971). In both groups, the majority of participants had a right manual preference (i.e., they stated that they used their right hand for both items). There were no significant differences between visually impaired and sighted participants in terms of manual preference distribution, as indicated by a $2 \times 2$ chi-square test, $\chi^{2}(N=138)=0.50, p=0.48, n s$.

-Insert Table 1 about here-

Participants in the visually impaired group were either blind (legally or totally blind, $n=16$, or $23 \%$ ), or had low vision ( $n=53$, or $77 \%$ ) according to the World Health Organization categorization system. They attended special centers for blind and visually impaired individuals in southern French cities. For most of them $(n=60$, or $87 \%)$, the visual deficiency was congenital, and in the remaining cases $(n=9$, or 13\%) it was acquired in infancy or childhood (age at onset of visual impairment varied between 3 months and 9 years).

Etiologies of visual deficiency were varied (e.g., aniridia, cataract, coloboma, glaucoma, Leber's congenital amaurosis, optic atrophy, retinitis pigmentosa). The visually impaired participants could read and write black script $(n=45$, or $65 \%)$, Braille $(n=13$, or $19 \%)$, or both black script and Braille ( $n=11$, or $16 \%$ ), with varying levels of expertise, depending on their chronological age. Unlike previous studies involving visually impaired participants, we did not exclude participants who had other disabilities in addition to their visual impairment, such as cognitive (e.g., langage impairment), sensory (e.g., deafness), or neurological (e.g., epilepsy) disorders. In our sample, 38\% (26 out of 69) of the visually impaired participants had an associated disorder, as reported by the professionals (psychologists, teachers, and ophtalmologists) working at the centers. Specific details on the presence and nature of these associated disorders, as well as the nature and cause of the deficiency and other relevant characteristics of the visually impaired participants are provided in Appendix A. Participants in the sighted group had a normal range of cognitive abilities, and none of them had additional needs (as reported by their parents and teachers). 
Informed written consent was obtained from the parents of the children and adolescents aged under18, and from the young adults themselves prior to their enrollment in the study. The study was conducted in accordance with the principles of the World Medical Association Declaration of Helsinki regarding ethical principles for research with human subjects.

\subsection{Materials and tests}

The materials consisted of raised stimuli (dots, lines, shapes, patterns, or pictures) printed on swell paper (21 x $29.7 \mathrm{~cm}$, landscape format), a wooden apparatus with an opaque curtain, and a stopwatch. The wooden apparatus was used to enable participants to put their hand behind the curtain to explore the stimuli through active touch, whilst preventing them from seeing the raised materials. The battery included 11 tests, divided into five categories, intended to measure scanning skills, tactile discrimination skills, spatial comprehension skills, short-term memory and picture comprehension. The tests are described below, together with the specific raised stimuli used in each test. Figure 1 provides examples of some of the materials used for the haptic tests.

-Insert Figure 1 about here-

The number of items per test was six (scanning tests, discrimination tests, and spatial tests), eight (picture comprehension tests), or twelve (short-term memory tests). To make betweenscore comparison easy, we decided to keep constant the maximum score for each test at 12 points. Thereby, we awarded two points per correct answer for tests including six items, one point and a half for tests including eight items, and one point per answer for tests including twelve items.

\subsubsection{Scanning tests}

This category included two tests: a dot scanning test that assessed participants' ability to exhaustively scan a raised-dot display, and a line scanning test that assessed their ability to scan raised lines without losing contact.

Our dot scanning test was similar to the efficient dot scanning subtest used by Ballesteros et 
al. (2005). It presented participants with a series of six test items featuring an increasing number of raised dots $(2,3,4,5,6$, and 15$)$, plus an initial practice card (with a single dot). It required participants to point to each dot with the index finger of their dominant hand, so as not to omit any dot on the page or point to the same dot more than once. The diameter of each raised dot was $0.25 \mathrm{~cm}$, and the raised dots were distributed nonlinearly across the page. Items were presented in a booklet. Instructions were as follows: "This card has a dot. Search for it with your fingertip and point to where the dot is with your finger." The examiner then removed the practice card and presented the six test cards one at a time, starting with the lowest number of dots. For each one, the instruction was: "On this card there are more dots. Search for them, and each time you find out one, just tell me by pointing to the dot." The examiner awarded two points for each card in which the participant had pointed to all the dots, without making a mistake (i.e., no misses or double hits). The maximum score was 12 points.

Our line scanning test was adapted from the graph and diagram subtest used by Ballesteros et al. (2005). This test presented participants with a series of six test items (two curvilinear lines, two rectilinear lines with right angles, and two rectilinear lines with acute angles), plus a first practice card (with a short curvilinear line). It required participants to follow each raised line with the index finger of their dominant hand, without losing contact with the line. Each line covered approximately an $8 \times 11 \mathrm{~cm}$ area on the page; each had a raised circle located on the left side, which made the starting point for following the line easy to detect. Items were presented in a booklet, in a constant order for test items (from curvilinear to rectilinear with acute angles). Instructions were as follows: "On this card, there is a line, which can take several turns. A small circle indicates the start of the line. Search for the circle on the left side, then follow the line with your finger without losing contact with it. You must not lift your finger up until you reach the end of the line." The examiner removed the practice card and then presented the six test cards one at a time, repeating the instruction each time. The examiner awarded two points for each card in which the participant managed to trace the whole line, without losing contact. The maximum score was 12 points.

\subsubsection{Haptic discrimination tests}

This category included three tests (texture discrimination, shape discrimination, and size discrimination), which assessed participants' ability to match raised-line elements on their texture, shape or size. In each test, participants were presented with a series of six test items 
(preceded by a practice trial). Items were presented in a booklet, in a constant (randomly determined) order. For each item, participants were first presented with a single stimulus (the benchmark), which they had to explore and memorize using their dominant hand. Next, they were presented with a series of four comparison stimuli (three distractors plus the target), which they had to explore one after the other (from left to right). For each comparison stimulus, participants had to indicate whether or not the stimulus was identical to the benchmark. The matching test was performed on the basis of a memorized representation of the benchmark, as participants were not allowed to return to the standard while they were exploring the comparison series. Criteria for constructing the comparison series were as follows: the location of the target stimulus in the comparison series varied across test items such that it was never located in the initial position (this was done to avoid an immediate touch with the target item as participants read the comparison series from left to right), and its location (second, third or fourth position) was repeated twice across the test items.

In our texture discrimination test, stimuli were raised-line squares filled with different textures. The textures were taken from Nolan and Morris' set of textures (Nolan \& Morris, 1971; see also Lederman \& Kinch, 1979). Each square measured 4 x 4 cm. Instructions were as follows: "On this card, there is a square that contains a special texture. Explore the square with your fingers, paying careful attention to its texture, and memorize it." The examiner then replaced the card featuring the benchmark with one featuring the comparison stimuli, and said: "On this new card, there are four squares. Explore them one by one with your fingers, and for each one tell me if the texture is the same as the one you explored in the previous card." The examiner awarded two points per correct recognition of the target stimulus with no errors (no false detection). The maximum score was 12 points.

In our shape discrimination test, the stimuli were complex raised-line geometric shapes (e.g., half circle, ellipse, parallelogram, star). Each shape fitted inside a 3 x $3 \mathrm{~cm}$ area. Instructions were as follows: "On this card, there is a geometric shape. Explore it with your fingers, paying careful attention to its shape, and memorize it". The examiner then replaced the card featuring the benchmark with one featuring the comparison stimuli, and said: "On this new card, there are four shapes. Explore them one by one with your fingers, and for each one tell me whether the shape is the same as the one you explored in the previous card." The examiner awarded two points per correct recognition of the target stimulus with no errors (no false detection). The maximum score was 12 points. 
In our size discrimination test, the stimuli were basic raised-line geometrical shapes (square, triangle, and circle) measuring $2 \mathrm{~cm}, 3 \mathrm{~cm}, 4 \mathrm{~cm}$, or $5 \mathrm{~cm}$ in length or diameter. The comparison shapes were ranked in increasing order of size $(2-3-4-5 \mathrm{~cm})$. There were two test items per basic geometric shape. Instructions were as follows: "On this card, there is shape of a particular size. Explore it with your fingers, paying careful attention to its size, and memorize it." The examiner then replaced the card featuring the benchmark with one featuring the comparison stimuli, saying as she did so: "On this new card, there are four shapes of different sizes. Explore them one by one with your fingers, and for each one tell me whether it is the same size as the one you explored in the previous card." The examiner awarded two points per correct recognition of the target stimulus with no errors (no false detection). The maximum score was 12 points.

\subsubsection{Spatial comprehension tests}

This category included two tests, which assessed participants' ability to match raised figures of increasing complexity on the basis of either the spatial orientation of their constituent segments (spatial orientation test) or the spatial location of their internal elements (spatial location test). In both tests, participants were presented with a series of six test items (preceded by a practice trial). These items were presented in a booklet, in a constant order (from simple to more complex test items). Each item involved the presentation of a benchmark stimulus, followed by the presentation of a series of four comparison stimuli. Participants had to indicate whether or not each comparison stimulus was identical to the benchmark. They were not allowed to return to the standard while they were exploring the comparison series. Criteria for constructing the comparison series were similar to those used and described in the haptic discrimination tests.

The stimuli in our spatial orientation test were raised-line figures made up of one, two, or three rectilinear segments, each segment having a specific orientation (horizontal, vertical, or oblique). Each segment measured $3 \mathrm{~cm}$ long. The practice item was a one-segment figure, while the test items included two items with one segment, two items with two segments, and two items with three segments (presented in order of increasing complexity). Participants explored the rectilinear segments with the index finger of their dominant hand. Instructions were as follows: "On this card, there is a figure made up of one/several line(s). Explore it with your index finger, paying careful attention to line(s) orientation, and memorize it." The examiner then replaced the card featuring the benchmark with the one featuring comparison 
stimuli, and said: "On this new card, there are four figures made up of one/several line(s). Explore them one by one with your index finger, and for one each tell me whether the figure has the same spatial orientation as the one you explored in the previous card." The examiner awarded two points per correct recognition of the target stimulus with no errors (no false detection). The maximum score was 12 points.

The stimuli in our spatial location test were raised-line figures in the shape of a circle (diameter $=4 \mathrm{~cm}$ ) containing one, two or three small elements (plain square, circle, or star). The size of these geometric elements varied from 7 to $10 \mathrm{~mm}$. The practice item was a oneelement figure, while the test items included three items with one-element figures, two items with two-element figures, and one item with a three-element figure (presented in order of increasing complexity). Participants used the fingers of their dominant hand to explore the elements inside the circles. Instructions were as follows: "On this card, there is/are one/several geometric element(s) inside a circle. Explore the circle with your fingers, paying careful attention to the location of the element(s) within the circle, and memorize it." The examiner then replaced the card featuring the benchmark with one featuring the comparison stimuli, and said: "On this new card, there are four circles. Explore them one by one with your fingers, and for each circle tell me whether the element(s) are in the same location as in the circle you explored on the previous card." The examiner awarded two points per correct recognition of the target stimulus with no errors (no false detection). The maximum score was 12 points.

\subsubsection{Short-term memory tests}

This category included two tests, which assessed the participants' ability to memorize and recall either a series of raised dots (dot span test) or a series of raised-line geometric shapes (shape span test) in the right order. These tests were adapted from the dot span subtest used by Ballesteros et al. (2005). Both tests were span tests involving the presentation of increasingly long series of stimuli (from one to six stimuli), which participants explored from left to right, and had to memorize. Immediately after exploring each series, participants had to report the names of the stimuli in the right order. The session started with the presentation of a practice card containing the full set of stimuli. This practice card ensured that participants could correctly name each stimulus. The ensuing test session began with a one-item series, and continued with series of increasing lengh (i.e., up to six-item series). There were two trials per series (i.e., 12 series altogether). Criteria for constructing the series were as follows: (i) each 
stimulus appeared only once in a given series; (ii) the location of a given stimulus varied across the series; and (iii) the last stimulus of one series differed from the first stimulus of the next series. Items were presented in a booklet, in a constant order (from one- to six-item series). The session stopped when participants failed to report two series of a similar length in the right order.

In our dot span test, the stimuli were raised-line rectangles containing one to six raised dots. The dots inside the rectangles were arranged like the dots on a domino. Each rectangle measured $2 \times 2.6 \mathrm{~cm}$. The diameter of each raised dot was $0.1 \mathrm{~cm}$. Participants used the index finger of their dominant hand to explore series of increasing length from left to right. Instructions were as follows: "On this card, there is/are one/several domino(es). Explore them one by one with your index finger, and memorize the number of dots on each domino. Once you have finished exploring all the dominoes, tell me the number(s) in their order of appearance." The examiner awarded one point per series when the participant had reported all the numbers in the correct order of appearance, without making any errors (omission or inversion). The maximum score was 12 points.

In our shape span test, the stimuli were raised-line geometric shapes (circle, square, triangle, star, cross, and rectangle). The average size of the shapes was $2 \times 2 \mathrm{~cm}$. Participants used the fingers of their dominant hand to explore series of increasing lengh (one to six) from left to right. Instructions were as follows: "On this card, there is/are one/several shapes in a row. Explore them one by one with your fingers, and memorize the shapes. Once you have finished exploring all shapes, tell me the names of the shapes in their order of appearance." The examiner awarded one point per series when the participant had reported all the names of shapes in the correct order of appearance, without making errors (omission or inversion). The maximum score was 12 points.

\subsubsection{Picture comprehension tests}

This category included two tests, which assessed the participants' ability to identify complete (picture identification test) and incomplete (picture completion test) raised-line pictures of common objects. In both tests, participants were presented with a series of eight test items (plus two practice trials). These items were presented in a booklet, in a constant (randomly determined) order. Participants had to identify the object depicted in the pictures (plus its 
missing feature in the case of incomplete pictures).

Our picture identification test was taken from pilot studies by Picard et al. (2013, 2014). These pilot studies indicated that the selected pictures could be recognized and tested through raised line drawing efficiently by sighted as well as by visually impaired participants. Stimuli were eight raised-line drawings of familiar objects: banana, apple, dog, butterfly, sock, shoe, car, and bicycle. Practice stimuli were a spoon and a table. Maximum picture size was 19 x 25 $\mathrm{cm}$. Pictures contained only two-dimensional information and were simplified versions of pictures developed by Snodgrass and Vanderwart (1980). Participants were told to freely explore each drawing with both hands, and to identify what it represented, as quickly and accurately as possible. Following the procedure used by Heller, Calcaterra, Burson, and Tyler (1996), participants were given the category name of the object, when each picture was presented (fruit for banana and apple; animal for dog and butterfly; clothes for shoe and sock; vehicle for car and bicycle). This option was selected because pre-tests had indicated that picture identification without providing participants with semantic cues results in floor-level performances by children. Instructions were as follows: "On this card, there is a drawing of familiar object. Carefully explore the picture with your hands, and tell me what the drawing represents, as accurately and quickly as possible. You have a maximum of two minutes to give me an answer. The drawing is that of a [category name]." Using a stopwatch, participants were timed from the moment they first touched a picture to the time they verbally gave a response. For each card, the examiner awarded 1.5 points when the participant provided the expected name (or a close synonym) of the object. The maximum score was 12 points.

Our picture completion test was taken from a pilot study by Mazella et al. (2014b). Stimuli were eight raised-line drawings of familiar objects each with a missing element: a human with a missing leg, a hand with a missing nail, a comb with missing teeth, a ladder with missing rungs, a sweater with a missing sleeve, a guitar with no strings, and a clock with no hands. Practice stimuli were a house with no door and a pig with no tail. Maximum picture size was 19 x $25 \mathrm{~cm}$. The pictures contained only two-dimensional information, and were simplified and adapted from the image completion subtest of the WISC-IV-R. Participants were told to freely explore each drawing with both hands, and to identify what the drawing represented, as well as the identity of the missing feature, as quickly and accurately as possible. They were given categorical information about the object when the picture was presented (shadow for human; part of the body for hand; small object you can hold in your hand for comb and scissors; object used by firefighters for ladder; clothes for sweater; musical instrument for 
guitar; object that tells the time for clock). This option was selected because pre-tests had indicated that the identification of incomplete pictures results in floor-level performances by children when they are not provided with semantic information. Instructions were as follows: "On this card, there is a drawing of familiar object with a missing element. Carefully explore the picture with your hands, and tell me what the drawing represents and which element is missing, as accurately and quickly as possible. You have a maximum of two minutes to give me an answer. The drawing is that of a [information about the object]." Using a stopwatch, participants were timed from the moment they first touched a picture till the time they verbally gave a response. The examiner awarded a maximum of 1.5 points for each card when participants provided the expected name (or a close synonym) of the object ( 0.75 points), and its missing fetaure ( 0.75 points). The maximum score was 12 points.

\subsection{Procedure}

A female psychologist administered the tests. Participants aged 5-11 years were observed at school, and those aged 12-25 years were observed at home. All participants were tested individually in a quiet room and were comfortably seated at a table. Participants were administered all five categories of tests (eleven haptic tests), with 5-min breaks between two successive categories of tests. The order of presentation of the five categories of tests was counterbalanced across participants of each age group, according to a Latin square technique. Within each category, the order of presentation of the tests was also counterbalanced across participants. The test lasted 60 minutes per participant, on average. However, the duration of the testing period varied greatly according to the participants' age, alertness, and motivation. For the children, the tests were often spread across two sessions.

\subsection{Performance measures on the 2D-haptic battery}

For each participant, performance measures on the haptic battery included a score for each of the eleven haptic tests (range $=0-12$ points), and a composite score that corresponded to the sum of all these scores (range $=0-132$ points). It should be noted that, in the picture identification and completion tasks, we also recorded response times, although they were not subjected to statistical analysis for the purposes of the present paper. 


\subsection{Additional assessments}

These additional assessments were conducted on a restricted part of the original sample of sighted and visually impaired participants. Participants with additional disorder to their visual impairment were not included in these additional assessments.

\subsubsection{Test-retest reliability}

In order to assess the consistency of the measurements over time, $9 \%(n=12)$ of the original sample underwent a retest procedure between one and two months after the full haptic test battery was first administered. The test-retest sample included six sighted and six visually impaired participants whose ages ranged from 59 to 254 months (mean age $=12$ years 5 months, $S D=5$ years 6 months).

\subsubsection{Convergent validity}

To assess the convergent validity of the 2D-Haptic test battery, 34\% $(n=47)$ of the original sample was also tested on the B101-DV (Bonnardel, Baton, \& Thiébaut, 2010; Theurel \& Gentaz, 2014). This subsample included 24 sighted and 23 visually impaired participants whose ages ranged from 90 to 188 months (mean age $=10$ years 10 months, $S D=2$ years 4 months). The B101 is a French adaptation of the Kohs Block Design Test, in which participants are asked to reproduce a meaningless geometric pattern using tactile blocks (both the blocks and the components of the patterns are covered with plastic or fabric). We chose to administer the B101 to assess convergent validity because this test measures nonverbal spatial reasoning, and is a haptic performance test involving perceptual-motor and cognitive skills.

\subsubsection{Discriminant validity}

To assess the discriminant validity of the 2D-Haptic test battery, $45 \%(n=62)$ of the original sample was also tested on the verbal subscale of the WISC-IV-R. This subsample included 26 sighted and 36 visually impaired participants whose ages ranged from 89 to 190 months (mean age $=11$ years, $S D=2$ years 7 months). The WISC verbal subscale consists of three subtests: similiarities, vocabulary, and comprehension. The similarities subtest, which asks participants to say how two seemingly dissimilar objects might, in fact, be similar, assesses logical thinking, verbal concept formation and verbal abstract reasoning. The vocabulary 
subtest, which asks participants to define a list of words, assesses verbal fluency, concept formation, word knowledge, and word usage. The comprehension subtest asks participants to explain what should be done in certain circumstances, the meaning of proverbs, or why certain societal practices are followed. This subtest assesses social knowledge and the ability to understand and adapt to social customs. We chose to administer the verbal subscale to assess discriminant validity because it measures verbal intelligence, and not haptic performance. It has already been used to assess the discriminant validity of haptic performance tests (see, for example, the 3D-Haptic Matrix Test of nonverbal reasoning; Miller et al., 2007).

\subsection{Statistical analyses}

Preliminary analyses (Shapiro-Wilk tests) were run on the composite haptic score to check the normality of data distribution for the sighted and visually impaired participants in each age group. We then conducted a series of psychometric analyses. First, the internal consistency of the haptic tests was assessed, using Cronbach's alpha and split-half reliability coefficients. Second, we examined test-retest reliability using Spearman's rho correlation, owing to the small size of the subsample. We additionally compared mean values obtained at test and retest using the Wilcoxon matched-pairs test. Third, convergent and discriminant validities were both determined using Pearson's correlation coefficients. Fourth, the factorial structure of the battery was assessed with exploratory factor analysis (EFA) using principal component analysis with varimax rotation. This was followed up with factor analysis (CFA) using the maximum likelihood method. Finally, we examined 2D-Haptic's developmental sensitivity and differential aspects. Variations in scores according to age group and/or vision (normal, impaired) were assessed using factorial analyses of variance (ANOVAs). Analyses of covariance (ANCOVAs with age as a controlled variable) were run to test the effects of visual status (low vision, legal blindness, total blindness), associated disorder (absent, present), and braille reading (yes/no) on the scores obtained by the visually impaired participants. We set the alpha level at 0.05 for all statistical analyses. When multiple comparisons were run, we corrected the alpha level using the Bonferroni method. All statistical analyses were conducted using Statistica 12.0 software, except for the CFA, for which we used Lisrel 9.10 (Joreskog \& Sorbom, 2012). 
As suggested by one reviewer, the inclusion of participants with additional disorder to their visual impairment in our sample of subjects may be concerning (e.g., it may have alter our findings). Therefore, whenever necessary, we re-run all the analyses without participants having additional disorder (data from 26 participants were thus excluded; $\mathrm{N}=112=43$ visually impaired participants without additional disorder +69 sighted controls), and added a note on the resulting findings. Overall, the exclusion (vs. inclusion) of these 26 participants did not change fundamentally the results.

\section{Results}

Shapiro-Wilk tests indicated that the data distribution of the composite haptic scores did not deviate significantly from normality for the sighted and visually impaired participants in each age group (5-6 years: sighted, $\mathrm{W}=0.97621, p>0.95$, visually impaired: $\mathrm{W}=0.91294, p>$ 0.20 ; 7-8 years: sighted, $\mathrm{W}=0.88353, p>0.07$, visually impaired, $\mathrm{W}=0.88873, p>0.09$; 9-10 years: sighted, $\mathrm{W}=0.94577, p>0.53$, visually impaired, $\mathrm{W}=0.95385, p>0.65 ; 11-14$ years: sighted, $\mathrm{W}=0.93595, p>0.40$, visually impaired, $\mathrm{W}=0.91568, p>0.21 ; 15-18$ years: sighted, $\mathrm{W}=0.98694, p>0.99$, visually impaired, $\mathrm{W}=0.92010, p>0.25)$. The composite haptic scores also appeared to be distributed normally for the sighted and visually impaired young adults, but the low number of values considered (four per group) prevented us from running the Shapiro-Wilk tests for this specific age group.

\subsection{Psychometric properties of the 2D-Haptic test battery}

\subsubsection{Internal consistency}

Table 2 reports Cronbach's $\alpha$ and the split-half reliability coefficient for each haptic test. It should be noted that we did not calculate Cronbach's alpha and the split-half coefficient for the dot span and shape span tests because these short-term memory tests each yielded a single score.

-Insert Table 2 about here-

Results (Table 2) revealed moderate to high reliability coefficients. Cronbach's $\alpha$ ranged from 0.51 (size discrimination) to 0.84 (picture completion). The split-half coefficients ranged from 
0.56 (texture discrimination) to 0.83 (picture completion). Both methods for assessing item reliability showed consistent results. Items within each test were also examined, with a view to eliminating those with extreme values or minimal variance (thus potentially lowering internal consistency). As no such items were found, and considering the moderate to high reliability coefficients we obtained, we decided to keep all the original items in each test of the haptic test battery for subsequent analyses.

Note that similar findings were obtained when participants with additional disorder to their visual impairment were excluded from the analyses. Cronbach's $\alpha$ ranged from 0.53 (size discrimination) to 0.87 (picture completion), and the split-half coefficients ranged from 0.54 (texture discrimination) to 0.85 (picture completion).

\subsubsection{Test-retest reliability}

Table 3 shows the mean scores at test and retest on the 2D-Haptic battery. When all tests were taken together, mean retest scores $(M=82.02, S D=24.02)$ were slightly higher than mean test scores $(M=77.10, S D=23.51)$, suggesting that participants either improved their performances between test and retest, or else felt more confident with the haptic battery at retest. However, when we looked at the mean scores for each individual haptic test, we found that the increase between test and retest only concerned four of the 11 tests (i.e., shape discrimination, spatial orientation, picture identification, and picture completion).

-Insert Table 3 about here-

Statistical analyses indicated that none of the observed variations in the mean scores between test and retest were significant (all $p s>0.004$, with Bonferroni correction). In addition, there was a high and significant correlation coefficient between composite scores at test and retest $\left(r_{\mathrm{s}}=0.93, p<0.0001\right)$. When the correlation analyses were run test by test, significant correlations between the scores at test and retest emerged for the picture completion test $\left(r_{\mathrm{s}}=\right.$ 0.89), shape span test $\left(r_{\mathrm{s}}=0.91\right)$, dot span test $\left(r_{\mathrm{s}}=0.92\right)$, and size discrimination test $\left(r_{\mathrm{s}}=\right.$ 0.92). Taken together, these findings indicated that the $2 \mathrm{D}$-Haptic test battery had satisfactory test-retest reliability.

\subsubsection{Convergent validity}


Table 4 displays the partial correlation coefficients (controlling for age) between scores on the 2D-Haptic battery and scores on the B101. Results showed that the composite haptic scores were significantly correlated with scores on the B101 $\left(r_{p}=0.51, p=0.000\right)$. Inspection of the correlation coefficients for each individual haptic test also revealed significant relationships between B101 scores and the dot-span $\left(r_{p}=0.49, p=0.001\right)$ and picture completion $\left(r_{p}=0.44\right.$, $p=0.001)$ scores. On the whole, results indicated that 2D-Haptic scores correlated moderately closely with B101 scores, thereby attesting to the validity of our battery.

-Insert Table 4 about here-

\subsubsection{Discriminant validity}

Table 5 sets out the partial correlation coefficients (controlling for age) between scores on the 2D-Haptic test battery and raw scores on the WISC verbal subscale. The composite haptic scores were significantly (but moderately) correlated with the verbal WISC scores $\left(r_{p}=0.43\right.$, $p=0.001)$. More specifically, the composite haptic scores correlated with scores on the similarities subtest $\left(r_{p}=0.40, p=0.001\right)$, but not with scores on the vocabulary or comprehension subtests. When we looked at the correlations between verbal WISC scores and the scores on each haptic test, we found that the dot-span $\left(r_{p}=0.42, p=0.001\right)$ and picture completion $\left(r_{p}=0.44, p=0.001\right)$ scores correlated significantly with raw scores on the verbal WISC. In addition, significant correlations emerged between the dot-span and similarities scores $\left(r_{p}=0.41, p=0.001\right)$, as well as between the picture completion and comprehension scores $\left(r_{p}=0.42, p=0.001\right)$. Overall, results showed that correlations between the 2D-Haptic and verbal WISC scores were only slightly weaker than those between the 2D-Haptic and B101 scores, thus attesting to our battery's discriminant validity.

-Insert Table 5 about here-

\subsubsection{Factorial structure}

Firstly, we ran an EFA on the raw scores for all 138 participants on all 11 haptic tests, using principal component analysis with varimax rotation. The optimum number of factors was determined using a combination of the Kaiser criterion (factors with eigenvalues greater than 
one should be retained for interpretation; Kaiser, 1960) and Cattell's scree test (scree plot for eigenvalues is examined to determine the point at which the last significant drop takes place; Cattell, 1966). Accordingly, a three-factor solution was retained. This model explained $70.06 \%$ of the total variance. The first factor had an eigenvalue of 5.8 and explained $52.75 \%$ of the variance, the second factor had an eigenvalue of 1.07 and explained $9.7 \%$ of the variance, and the third factor had an eigenvalue of 0.83 and explained $7.6 \%$ of the variance. Table 6 shows the descriptive statistics and the factor loadings yielded by the EFA.

-Insert Table 6 about here-

As can be seen in Table 6, the factor loadings of the matrix structure were all above 0.60 on a single dimension. The first latent factor loaded on the following tests: texture discrimination (0.76), shape discrimination (0.67), size discrimination (0.61), spatial orientation (0.68), spatial location (0.77), dot span (0.61), and shape span (0.60). Factor 1 was labelled raisedshape processing, because the tests on which it loaded all involved the encoding, memory and recognition of haptically perceived raised shapes. The second latent factor loaded highly on dot scanning (0.90), and line scanning (0.70). This factor was labelled sequential scanning, as it loaded on tests involving the sequential scanning of either raised dots or lines through haptics. The third and last latent factor loaded highly on picture identification (0.91), and picture completion (0.78). This factor was labelled raised-line object identification, because it loaded on tests involving the recognition of complete or incomplete raised-line drawings.

Note that similar findings were obtained when we excluded from the EFA the 26 visually impaired participants with additional disorder. A three-factor structure emerged (eigenvalues: factor $1=5.96$, factor $2=1.08$, factor $3=0.73$ ), with the model explaining $70.79 \%$ of the variance. The factor loadings were all above 0.60 (range $=0.62$ to 0.89 ), and the association between tests and factors remained unchanged.

Second, we ran a CFA to test the three-factor model's fit to the 11-test battery, using the maximum likelihood method. A three-factor model was tested in which Tests 3-9 (see Table 6) loaded on the first latent factor (raised-shape processing), Tests 1 and 2 loaded on the second latent factor (sequential scanning), and Tests 10 and 11 loaded on the third latent factor (raised-line object identification). Figure 2 displays the path diagram yielded by the CFA for the three-factor solution. 
-Insert Figure 2 about here-

Figure 2 shows satisfactory factor loadings for each latent factor (range: 0.57-0.94), and satisfactory correlations between the three latent factors (between the first and second factors: $r=0.68$; between the first and third factors: $r=0.79$; between the second and third factors: $r$ $=0.61)$. The CFA yielded an acceptable goodness-of-fit index $(\mathrm{GFI}), \chi^{2}(41)=65.46, p=$ 0.00894 (with $\chi^{2} / d f<3$, as recommended by Wheaton, Muthén, Alwin, \& Summers, 1977). Additional fit indices were also acceptable: the GFI was 0.952, the comparative fit index (CFI) was 0.974, and the root mean square error of approximation (RMSEA) was 0.066 (see Jackson, Gillaspy, \& Purc-Stephenson, 2009, for recommended values). Thus, the three-factor model was fully relevant.

Similar conclusions were drawn when we excluded from the CFA the 26 visually impaired participants with additional disorder. Factor loadings for each latent factor ranged 0.58 to 0.93. Correlations between factors ranged $0.66\left(1^{\text {st }}-2^{\text {nd }}\right.$ factors $)$ to $0.83\left(1^{\text {st }}-3^{\text {rd }}\right.$ factors $)$. Fit indices were all acceptable: $\chi^{2}(41)=49.01, p=0.18256$; GFI $=0.932$; CFI $=0.995$; RMSEA $=0.042$.

3.2. Developmental sensitivity and differential aspects of the 2D-Haptic battery

\subsubsection{Variations in haptic scores according to age group and/or vision (normal, impaired)}

Table 7 summarizes the $p$ values for the main and interaction effects of age and vision on the composite haptic score and individual test scores. Descriptive statistics for all the haptic scores (mean and $S D$ ) obtained by participants with normal or impaired vision in the different age groups are provided in Appendix B.

-Insert Table 7 about here-

As Table 7 shows, age was a significant factor for variation in all the haptic scores, with medium to high effect sizes. By contrast, we failed to find any significant effects of vision, and the Age $\mathrm{x}$ Vision interaction effects were never significant. Closer inspection of the data (see Appendix B) indicated that there was a clear improvement with age in all haptic scores. 
First, the composite haptic score (maximum value $=132$ points) increased from a mean value of 43.71 points $(S D=14.85)$ to 114.59 points $(S D=9.48)$ between 5-6 years and young adulthood. Second, similar improvements in scores were observed for each haptic test (where the maximum value was 12 points) across the same period. The mean scores of the youngest children (5-6 years) were generally low, but never at floor level (range $=2.31-5.85$, with a minimum value of 2.31 for the dot span task), while the mean scores recorded in the young adult group were generally high, but never at ceiling level (range $=8.75-11.50$, with a maximum value of 11.50 for the line scanning task). Thus, our haptic test battery displayed a strong and significant developmental sensitivity.

Note that the conclusions remained unchanged when the participants with additional disorder to their visual impairment were removed from the analyses (i.e., age was still the only significant factor for variation in haptic scores).

Table 8 sets out the mean scores and standard error $(S E)$ on the haptic test battery for the lowvision, legally blind, and totally blind participants. As can be seen in Table 8, there was little variation in composite haptic scores according to visual status: the highest composite score was obtained by the legally blind participants $(M=80.86, S E=8.66)$, closely followed by the totally blind group $(M=73.79, S E=7.36)$, and the low vision group $(M=70.99, S E=2.96)$. The ANCOVA with age as a covariate did not yield a significant effect of visual status on composite haptic scores $(p=0.55)$. Similar nonsignificant effects of visual status were found when individual test scores were considered (all $p s>0.19$ ). Thus, there was no evidence for variation in haptic scores according to visual status, suggesting that despite different degrees of visual impairment, we could possibly use a single calibration for all visually impaired participants.

It should however be noted that the lack of significant difference in performance between the groups of visually impaired is surprising, especially as far as picture comprehension tasks are concerned (totally blind children who lack the understanding of visual perspective and how things look in two dimensions were likely to score significantly lower in tactile picture identification tasks compared to children with low vision). As pointed out by one reviewer, the fact that the ANCOVAs comparing the groups were not significant might also result from the difference in the sizes of the groups (low vision: 53, legally blind: 6, and totally blind: 10). 
-Insert Table 8 about here-

\subsubsection{Effect of associated disorders (absent, present) on the haptic scores of the visually impaired participants}

Table 9 reports the mean scores $(S E)$ on the 2D-Haptic test battery of the visually impaired participants with and without associated disorders. We acknowledge that putting participants with associated disorders together in a single group is a potential source of concern, owing to the broad variety of these disorders (see Appendix A). Furthermore, the limited size of our sample prevented us from distinguishing further between the different types of these associated disorders (e.g., cognitive, neurological, sensory), and running statistical analyses accordingly. Therefore, the present analysis was quite crude, and was simply intended to determine whether or not differences in scores emerged between participants who had a disorder in addition to their visual impairment and those with no associated disorder.

-Insert Table 9 about here-

Results provided in Table 9 show that the visually impaired participants with no associated disorder had higher composite haptic scores $(M=77.67, S E=3.06)$ than those with an associated disorder $(M=63.29, S E=3.94)$. Similar differences in scores between the two groups were observed for the individual haptic tests, with lower scores in the case of an associated disorder. However, the ANCOVA with age as a covariate revealed that the effects of associated disorders (absent, present) on the composite and individual haptic scores never reached significance (Bonferroni-corrected alpha), except for scores on the dot-span test. Participants who had a disorder associated with their visual impairment scored significantly lower on the dot-span test $(M=3.98, S E=0.52)$ than those with no associated $\operatorname{disorder}(M=$ $6.01, S E=0.40), p<0.003$. Thus, with the exception of an observed deficit in tactile memory span, there was no evidence for lower haptic scores in the case of an associated disorder.

-Insert Table 9 about here-

\subsubsection{Effect of Braille reading (yes, not) on the haptic scores of the visually impaired} participants 
Table 10 reports the mean scores $(S E)$ on the 2D-Haptic test battery of the visually impaired participants who read Braille $(\mathrm{n}=24)$ or black script only $(\mathrm{n}=45)$. Results indicated that the readers of Braille had higher composite haptic scores $(M=79.31, S E=4.46)$ than those who read black script only $(M=68.48, S E=3.17)$. As could be expected, the advantage of Braille over non-Braille readers was especially visible in performance obtained at the dot span test, in which items (small raised dots) resembled braille patterns. In this test, the Braille readers overperformed $(M=6.23, S E=0.59)$ readers of black script $(M=4.72, S E=0.42)$. However, the ANCOVA with age as a covariate revealed that the effects of Braille reading (yes, no) on the composite and individual haptic scores never reached significance (after Bonferronicorrected alpha).

-Insert Table 10 about here-

\section{Discussion}

The purpose of the present study was to design and validate a new haptic battery using 2D raised materials, so as to fill an important gap in the psychometric assessment of children and adolescents with impaired vision (see Mazella et al., 2014). This was the first research project to take a developmental approach to tactual abilities assessed with 2D raised materials, incorporating a comparison group (sighted participants working under visual occlusion) and measuring all the properties expected of a psychometric test. Overall, our findings indicated that Haptic-2D displays good psychometric properties in terms of sensitivity, reliability, and validity.

As far as sensitivity is concerned, Haptic-2D was intended to be a developmental battery, discriminating between participants' performances according to their chronological age. Its sensitivity was attested to by i) normal distributions of composite haptic scores for sighted and visually impaired participants in each age group, and ii) significant improvements with age in both composite and individual haptic scores. Neither floor nor ceiling performances were observed in the age range we considered. However, given that the young adults (20-25 years) scored quite highly, we suggest that the battery is most suited to measuring changes in tactual abilities between five and 18 years of age. Interestingly, we found no significant variation in haptic performances according to visual status, suggesting that children and 
adolescents with visual impairments (low vision, legal blindness, and total blindness) are not disadvantaged by our battery of tests, at least compared with sighted controls working under visual occlusion. Moreover, the performances of visually impaired participants with associated disorders did not differ significantly from those of visually impaired participants with no additional disability, except for one measure of short-term memory (dot-span test) where participants with associated disorders were characterized by small spans.

As far as reliability is concerned, Haptic-2D demonstrated both internal consistency ( $\alpha=$ $0.51-0.84)$ and satisfactory test-retest reliability $\left(r_{\mathrm{s}}=0.93\right)$. The reliability of our test items and measurements across time was very similar to that reported in previous research projects of the same vein. For instance, Ballesteros et al. (2005) reported Cronbach's alphas between 0.54 and 0.88 for their Haptic Battery, and Withagen et al. (2009) obtained a correlation coefficient of 0.94 for test-retest reliability for their Tactual Profile.

Finally, as far as validity is concerned, Haptic-2D had a satisfactory construct validity, as attested to by measures of convergent and discriminant validity. Convergent validity was good, as shown by a significant correlation (age partialled out) between composite haptic scores and scores on the B101 test $\left(r_{p}=0.51\right)$. Discriminant validity was also satisfactory, as attested to by a significant (but lower) partial correlation between composite haptic scores and raw scores on the WISC verbal subscale $\left(r_{p}=0.43\right)$. Interestingly, in our battery, the haptic scores that most closely correlated with scores on the B101 and verbal WISC were for picture completion and dot span, both adaptations of classic subtests in Wechsler's intelligence scales. These findings suggest that our battery partly measured the same psychological construct as the B101 test (a tactile adaptation of the Kohs design test; Bonnardel et al., 2010; Theurel \& Gentaz, 2014). It should be noted, however, that the observed correlation (0.51) was not as high as might have been expected, suggesting that the B101 test may not have been the most suitable instrument for measuring the convergent validity of our battery (or conversely that our scale did not have good convergent validity while the B101 test was a suitable option). Perhaps greater convergence might have been obtained using tests like the Tactual Profile (Withagen et al., 2009), Mommers' test (Mommers, 1974) or the Haptic Sensory Discrimination Test (Dial et al., 1990). Unfortunately, these tests have not yet been translated and validated for a French-speaking population. In our study, the observed correlation (0.43) between the composite haptic scores and raw scores on the verbal WISC was roughly comparable to those observed by Miller et al. (2007) between adults' scores on 
the verbal WAIS-III and scores on their 3D Haptic Matrix, a tactile equivalent of Raven's Progressive Matrices $(r=0.32)$, or by Dial et al. (1990) between adults' scores on the verbal WAIS-III and scores on their Cognitive Test for the Blind-Performance $(r=0.50)$.

We also explored the Haptic-2D's construct validity by investigating its factorial structure. We found that a three-factor model accounted for a high proportion (70\%) of the scores' total variance, and demonstrated fully statisfactory fit indices, $\chi^{2}(41)=65.46, p=0.00894, \mathrm{GFI}=$ $0.952, \mathrm{CFI}=0.974, \mathrm{RMSEA}=0.066$. These factors were interrelated, and identified as raised-shape processing (seven tests), sequential scanning (two tests), and raised-line object identification (two tests). It should be noted here that Ballesteros et al. (2005) found that a sixfactor model fitted their Haptic Battery, with three of these factors ressembling those highlighted here. However, one major difference between our battery and that of Ballesteros et al. is that we only designed tests in which participants interacted with $2 \mathrm{D}$ raised materials (not 3D objects and 2D raised materials). This difference may explain why we only found three relevant factors. Raised-shape processing (Factor 1) provided insight into the development of children's ability to encode, memorize, and recognize a variety of haptically perceived raised shapes. This ability is fundamental for processing the tactile shapes and patterns that visually impaired children encounter in the classroom. Sequential scanning (Factor 2) tested age-related improvements in children's ability to scan raised dots or lines through haptics. This ability is fundamental for detecting tactile items on a page, and is particularly important for learning and reading Braille (Millar, 1997). Raised-line object identification (Factor 3) assessed age-related changes in children's ability to recognize complete or incomplete raised-line drawings of common objects. This ability is fundamental for efficiently processing tactile pictures, or indeed any picture depicting objects that can be semantically named. Taken together, these three factors accounted for a range of perceptualmotor and cognitive abilities involved in the haptic processing of $2 \mathrm{D}$ raised materials. In sum, we argue that Haptic-2D is a performance battery using 2D raised materials to measure tactual functioning in terms of raised-shape processing, sequential scanning, and raised-line object identification.

To conclude, this research project provided empirical evidence that the haptic modality can serve as the basis for a new and much needed psychometric assessment in the field of visual deficiency, namely the measurement of the age-related efficiency with which children and adolescents process raised materials using their sense of active touch. We showed that Haptic- 
$2 \mathrm{D}$ is a sensitive, valid, and reliable psychometric instrument, which takes about one hour to administer. The time taken for the battery could even be shortened if one considers using only half of the tests falling under a single category (for instance, using only one of the two memory span tests, one of the two picture recognition tests). Despite the good psychometric properties of our 2D haptic battery, which could in the near future extends the range of psychometric instruments available to professionals (psychologists, teachers) working with young people who have impaired vision, at least two major limitations of our work have to be considered.

One limitation refers to variations between tests in the constraints imposed on the exploratory hand movements: with the exception of the picture comprehension tests where participants freely used their both hands, all tests had to be realized with one hand only (sometimes with the index finger only). Recent research by Morash and collaborators (Morash, Connell Pensky, \& Miele, 2013) has shown a perceptual advantage of using two hands or multiple fingers over a single index finger in blindfolded sighted adults, which specific benefits were task-dependent. Moreover, these authors found that blind participants benefited more from two hands or multiple fingers than sighted participants in haptic spatial tasks (see Morash, Connell Pensky, Tseng, \& Miele, 2014). Our constraints on haptic exploration may have disadvantage participants in some tasks, specifically in the scanning tests where only the index finger could be employed. As a matter of fact, scanning tests were found very challenging, and participants performed low at these tests. Additionally, participants with visual impairments often reported that they felt frustrated not being allowed to use both of their hands to perform some tests. Our constraints on haptic exploration may have disadvantage even more the visually impaired participants, and this may have contribute to the lack of significant difference in haptic performance between sighted controls and participants with visual impairments. For future scale development in this area, it would be useful to better control exploratory hand movements across tests or to have comparative data between haptic performances obtained under conditions of free versus constrained exploration in both blind and sighted subjects.

Another limitation of our work refers to differences between participants in the testing conditions due to the possibility of using (or not) noninformative vision during the haptic tests: unlike the blind participants, those with low vision or normal vision were able, to a certain extent, to use extrinsic visual coordinates or peripheral visual information which 
served as a reference frame during the haptic tests. Different studies have shown that noninformative vision improved haptic spatial perception (e.g., Newport, Rabb, \& Jackson, 2002; Luyat, Mobarek, Leconte, \& Gentaz, 2005). It is therefore possible that participants with some functional vision benefited more from our testing context than those with complete blindness. Our testing context was set up to be confortable as possible (i.e., participants with functional vision could keep their eyes open during testing, and the tactile stimuli were hidden behind a cover), given that it was very difficult to ask young children to wear blindfolds. For future scale development in this area, it would be useful to consider more carefully the potential role of the testing context, by collecting comparative data on haptic performances obtained when participants are wearing a blindfold or are exploring a stimulus behind a cover without blindfolded eyes.

\section{Acknowledgments}

This research is part of the first author's $\mathrm{PhD}$ thesis, for which she received financial support from the Toulouse \& Midi-Pyrénées center for research and higher education (PRES) (2012-2015). The authors are very grateful to the sighted and visually impaired participants who took part in the project, and to the pupils and teachers of the school in Marssac sur Tarn. They wish to thank E. Wiles-Portier for her proofreading of the paper. They also wish to thank Mélanie Labardin (psychologist), Sandra Mesnières (psychologist) and all the professionals working at the Cival-Lestrade (Ramonville Saint Agne, 31) and AlfredPeyrelongue (Ambarès, 33) centers for their involvement in this project. 
References

Atkins, S. (2011). Assessing the ability of blind and partially sighted people: Are psychometric tests fair? Birmingham: RNIB Centre for Accessible Information.

Ballesteros, S., \& Bardisa, D. (2002). Manual de la Bateria Haptica (Haptic Battery: Manual). Madrid: ONCE.

Ballesteros, S., Bardisa, D., Millar, D., \& Reales, J. M. (2005). The Haptic Test Battery: A new instrument to test tactual abilities in blind and visually impaired and sighted children. British Journal of Visual Impairment, 23, 11-24.

Ballesteros, S., Reales, J. M., Bardisa, D., \& Muniz, J. (2005). A haptic test battery to test tactual abilities in blind and visually impaired children. In S. Ballesteros \& M. Heller (Eds.), Touch, blindness and neuroscience (pp. 303-313). Madrid: Uned Press.

Bauman, M. K., \& Kropf, C. A. (1979). Psychological tests used with blind and visually handicapped persons. School Psychology Review, 8, 257-270.

Bonnardel, R., Baton, C., \& Thiébaut E. (2010). Test d'intelligence pratique pour déficients visuels: B101DV. Talant: Editions Les Doigts Qui Rêvent.

Cattell, R. B. (1966). The scree test for the number of factors. Multivariate Behavioral Research, 1, 245-276.

D’Angiulli, A., Kennedy, J. M., \& Heller, M. A. (1998). Blind children recognizing tactile pictures respond like sighted children given guidance in exploration. Scandinavian Journal of Psychology, 39, 187-190.

Dial, J., Mezger, C., Gray, S., Massey, T., Chan, F., \& Hull, J. (1990). Manual: Comprehensive Vocational Evaluation System. Dallas, TX: McCarron-Dial Systems.

Gibson, J. J. (1966). The senses considered as perceptual systems. Boston, MA: Houghton Mifflin.

Hannan, C. K. (2007). Exploring assessment processes in specialized schools for students who are visually impaired. Journal of Visual Impairment \& Blindness, 101, 69-79.

Hatwell, Y. (2003). Psychologie cognitive de la cécité précoce [Cognitive psychology of early blindness]. Paris: Dunod.

Hatwell, Y., Streri, A., \& Gentaz, E. (2003). Touching for knowing: Cognitive psychology of haptic manual perception. Amsterdam/Philadelphia: John Benjamins.

Heller, M. A., Calcaterra, J. A., Burson, L. L., \& Tyler, L. A. (1996). Tactual picture identification by blind and sighted people: Effects of providing categorical information. Perception \& Psychophysics, 58, 310-323. 
Jackson, D. L., Gillaspy, J. A., \& Purc-Stephenson, R. (2009). Reporting practices in confirmatory factor analysis: An overview and some recommendations. Psychological Methods, 14, 6-23.

Joreskog, K. G., \& Sorbom, D. (2012). LISREL 9.10. Chicago, IL: Scientific Software International.

Kaiser, H. F. (1960). The application of electronic computers to factor analysis. Educational and Psychological Measurement, 20, 141-151.

Kennedy, J. M. (1993). Drawing and the blind: Pictures to touch. New Haven, CT: Yale University Press.

Klatzky, R. L., \& Lederman, S. J. (2009). Human haptics. In L. R. Squire (Ed.), New encyclopedia of neuroscience (Vol. 5, pp. 11-18). Amsterdam: Elsevier.

Klatzky, R. L., Lederman, S. J., \& Metzger, V. A. (1985). Identifying objects by touch: An “expert system”. Perception \& Psychophysics, 37, 299-302.

Klatzky, R. L., Loomis, J. M., Lederman, S. J., Wake, H., \& Fujita, N. (1993). Haptic identification of objects and their depictions. Perception \& Psychophysics, 54, 170-178.

Lederman, S. J., \& Kinch, D. (1979). Texture in tactual maps and graphics for the visually handicapped. Journal of Visual Impairment \& Blindness, 73, 217-227.

Lederman, S. J., \& Klatzky, R. L. (2009). Haptic perception: A tutorial. Attention, Perception, \& Psychophysics, 71, 1439-1459.

Lederman, S. J., Klatzky, R. L., Chataway, C., \& Summers, C. (1990). Visual mediation and the haptic recognition of two-dimensional pictures of common objects. Perception \& Psychophysics, 47, 54-64.

Luyat, M., Mobarek, S., Leconte, C., \& Gentaz, E. (2005). The plasticity of gravitational reference frame and the subjective vertical: Peripheral information affects the oblique effect. Neuroscience Letters, 385, 215-219.

Mazella, A., Albaret, J.-M., \& Picard, D. (2014a). Haptic tests for use with children and adults with visual impairment: A Literature review. Journal of Visual Impairment \& Blindness, 108, 227-237.

Mazella, A., Albaret, J.-M., \& Picard, D. (2014b). Find the missing element! Haptic identification of incomplete pictures by sighted and visually impaired children. In M. Auvray \& C. Duriez (Eds.), EuroHaptics 2014, Part II, Lecture Notes in Computer Science, 8619, 27-33.

Millar, S. (1997). Reading by touch. London: Routledge.

Miller, J. C., \& Skillman, G. D. (2003). Assessors' satisfaction with measures of cognitive 
ability applied to persons with visual impairments. Journal of Visual Impairment \& Blindness, 12, 769-774.

Miller, J. C., Skillman, G. D., Benedetto, J. M., Holtz, A. M., Nassif, C. L., \& Weber, A. D. (2007). A three-dimensional haptic matrix test of nonverbal reasoning. Journal of Visual Impairment \& Blindness, 101, 557-570.

Mommers, M. J. C. (1974). Toetsing van intelligentie en van de haptische waarneming bij blinde kinderen [Assessment of intelligence and haptic perception in blind children]. Nijmegen: Instituut voor Onderwijskunde, Katholieke Universiteit Nijmegen.

Morash, V. S., Connell Pensky, A. E., \& Miele, J. A. (2013). Effects of using multiple hands and fingers on haptic performance. Perception, 42, 759-777.

Morash, V. S., Connell Pensky, A. E., Tseng, S. T., \& Miele, J. A. (2014). Effects of using multiple hands and fingers on haptic performance in individuals who are blind. Perception, 43, 569-588.

Nolan, C. Y., \& Morris, J. E. (1971). Improvement of tactual symbols for blind children: Final report. Louisville, KY: American Printing House for the Blind.

Newport, R., Rabb, B., \& Jackson, S. R. (2002). Noninformative vision improves haptic spatial perception. Current Biology, 12, 1661-1664.

Oldfield, R. C. (1971). The assessment and analysis of handedness: The Edinburgh inventory. Neuropsychologia, 9, 97-113.

Overvliet, K. E., Wagemans, J., \& Krampe, R. T. (2013). The effects of aging on haptic 2D shape recognition. Psychology and Aging, 28, 1057-1069.

Picard, D., \& Lebaz, S. (2012). Identifying raised-line drawings by touch: A hard--but not impossible--task. Journal of Visual Impairment \& Blindness, 106, 427-431.

Picard, D., \& Monnier, C. (2009). Short-term memory for spatial configurations in the tactile modality: A comparison with vision. Memory, 17, 789-801.

Picard, D., Albaret, J.-M., \& Mazella, A. (2013). Haptic identification of raised-line drawings by children, adolescents and young adults: An age-related skill. Haptics-e, 5, 24-28.

Picard, D., Albaret, J.-M., \& Mazella, A. (2014). Haptic identification of raised-line drawing when categorical information is provided: A comparison between visually impaired and sighted children. Psicologica, 35, 277-290.

Reid, J. M. V. (1995). Assessing the verbal and nonverbal ability of visually impaired adults. The British Journal of Visual Impairment, 13, 12-14.

Reid, J. M. V. (2002). Testing nonverbal intelligence of working-age visually impaired adults: Evaluation of the adapted Kohs Block Design Test. Journal of Visual Impairment \& 
Blindness, 96, 585-595.

Revesz, G. (1950). The psychology and art of the blind. London: Longmans Green.

Snodgrass, J. G., \& Vanderwart, M. A. (1980). A standardized set of 260 pictures: Norms for name agreement, image agreement, familiarity, and visual complexity. Journal of Experimental Psychology: Human Learning and Memory, 6, 174-215.

Theurel, A., \& Gentaz, E. (2014). L'évaluation standardisée du raisonnement spatial non verbal avec un test adapté des cubes de Kohs: Premiers résultats obtenus avec des enfants déficients visuels (malvoyants et non-voyants). Enfance, 1, 41-54.

Tillman, M. (1967). The performance of blind and sighted children on the Wechsler Intelligence Scale for Children: Study 1. International Journal of Education of the Blind, 16, 65-74.

Wechsler, D. (2005). WISC-IV, Echelle d'Intelligence de Wechsler pour Enfants et Adolescents. Paris: ECPA.

Wheaton, B., Muthén, B., Alwin, D. F., \& Summers, G. F. (1977). Assessing reliability and stability in panel models. In D. Heise (Ed.), Sociological methodology (pp. 84-136). San Francisco, CA: Jossey-Bass.

Withagen, A., \& Schellingerhout, R. (2004). Tactual profile: An assessment procedure for tactual functioning in children and adolescents: Validation of the instrument. In S. Ballesteros \& M. Heller (Eds.), Touch, blindness and neuroscience (pp. 323-333). Madrid: Uned Press.

Withagen, A., Baerwaldt, I., Blok, A. G., Ekkens, I. E., Hamelink, A., \& Vervloed, M. P. J. (2005). Tactual profile (manual). Kortenhoef, the Netherlands: Xsites BV.

Withagen, A., Verloed, M. P. J., Janssen, N. M., Knoors, H., \& Verhoeven, L. (2010). Tactile functioning in children who are blind: A clinical perspective. Journal of Visual Impairment \& Blindness, 1, 43-54.

Withagen, A., Vervloed, M. J., Janssen, N. M., Knoors, H., \& Verhoeven, L. (2009). The Tactual Profile: Development of a procedure to assess the tactual functioning of children who are blind. The British Journal of Visual Impairment, 27, 221-238. 
Table and Figure captions

Table 1. Characteristics of the participants $(N=138)$.

Table 2. Cronbach's alpha and split-half reliability coefficients for each haptic test.

Table 3. Mean scores and standard deviation $(S D)$ on the 2D-Haptic test battery at test and retest. Correlations between test and retest scores measured with Spearman's rho. Comparisons between mean values made using Wilcoxon matched-pairs tests.

Table 4. Partial correlation coefficients (controlling for age) between scores on the 2D-Haptic test battery and scores on the B101.

Table 5. Partial correlation coefficients (controlling for age) between scores on the 2D-Haptic test battery and raw scores on the WISC verbal subscale.

Table 6. Descriptive statistics and factor loadings from the exploratory factor analysis.

Table 7. Summary of $p$ values for the main and interaction effects of age and vision for each dependent variable. Partial eta squared is provided in brackets for significant effects.

Table 8. Mean scores on the 2D-Haptic test battery for low vision, legally blind, and totally blind participants. Comparison between mean values using ANCOVAs, with visual status (3) as a between-participants factor, and age in months as a covariate.

Table 9. Mean scores on the 2D-Haptic test battery of visually impaired participants with and without associated disorders. Comparison between mean values using ANCOVAs with associated disorder (2) as a between-participants factor, and age in months as a covariate.

Table 10. Mean scores on the 2D-Haptic test battery of visually impaired participants who are Braille readers or who only read black script. Comparison between mean values using ANCOVAs with Braille reader (2: yes/no) as a between-participants factor, and age in months as a covariate. 
Figure 1. Examples of some of the materials used in the haptic tests.

Figure 2. Path diagram yielded by the confirmatory factorial analysis. 
Table 1. Characteristics of the participants $(N=138)$.

\begin{tabular}{|c|c|c|c|c|c|c|c|c|}
\hline \multirow[b]{2}{*}{ Age group } & \multirow[b]{2}{*}{ Number } & \multicolumn{3}{|c|}{ Age (months) } & \multicolumn{2}{|l|}{ Sex } & \multicolumn{2}{|c|}{ Handedness } \\
\hline & & Mean & $S D$ & Range & Boys & Girls & Right & Left \\
\hline \multicolumn{9}{|c|}{ (a) Visually impaired participants } \\
\hline $5-6$ yrs & 13 & 70 & 6 & $62-77$ & 8 & 5 & 9 & 4 \\
\hline $7-8$ yrs & 13 & 97 & 7 & $89-107$ & 9 & 4 & 11 & 2 \\
\hline $9-10 \mathrm{yrs}$ & 13 & 121 & 6 & $109-131$ & 9 & 4 & 11 & 2 \\
\hline $11-14 \mathrm{yrs}$ & 13 & 158 & 6 & $132-176$ & 6 & 7 & 11 & 2 \\
\hline $15-18$ yrs & 13 & 197 & 18 & $180-222$ & 6 & 7 & 11 & 2 \\
\hline young adults & 4 & 279 & 21 & 254-304 & 2 & 2 & 4 & - \\
\hline Total & 69 & & & & 40 & 29 & 57 & 12 \\
\hline \multicolumn{9}{|c|}{ (b) Sighted participants } \\
\hline $5-6$ yrs & 13 & 74 & 7 & $63-83$ & 5 & 8 & 10 & 3 \\
\hline $7-8$ yrs & 13 & 94 & 5 & $85-101$ & 8 & 5 & 10 & 3 \\
\hline $9-10 \mathrm{yrs}$ & 13 & 122 & 6 & $108-130$ & 7 & 6 & 12 & 1 \\
\hline $11-14 \mathrm{yrs}$ & 13 & 152 & 16 & $132-176$ & 6 & 7 & 12 & 1 \\
\hline $15-18$ yrs & 13 & 198 & 13 & $183-216$ & 6 & 7 & 12 & 1 \\
\hline young adults & 4 & 261 & 10 & $251-271$ & 2 & 2 & 4 & - \\
\hline Total & 69 & & & & 34 & 35 & 60 & 9 \\
\hline
\end{tabular}


Table 2. Cronbach's alpha and split-half reliability coefficients for each haptic test.

\begin{tabular}{llll}
\hline & $\begin{array}{l}\text { Cronbach's } \\
\text { alpha }\end{array}$ & $\begin{array}{l}\text { Split-half } \\
\text { reliability }\end{array}$ & $\begin{array}{l}\text { Number of } \\
\text { items }\end{array}$ \\
\cline { 2 - 4 } Dot scanning & 0.77 & 0.81 & 6 \\
Line scanning & 0.76 & 0.73 & 6 \\
Texture discrimination & 0.57 & 0.56 & 6 \\
Shape discrimination & 0.65 & 0.63 & 6 \\
Size discrimination & 0.51 & 0.59 & 6 \\
Spatial orientation & 0.60 & 0.60 & 6 \\
Spatial location & 0.68 & 0.73 & 6 \\
Dot span & - & - & 12 \\
Shape span & - & - & 12 \\
Picture identification & 0.66 & 0.62 & 8 \\
Picture completion & 0.84 & 0.83 & 8 \\
\hline
\end{tabular}


Table 3. Mean scores and standard deviation $(S D)$ on the 2D-Haptic test battery at test and retest. Correlations between test and retest scores measured with Spearman's rho. Comparisons between mean values made using Wilcoxon matched-pairs tests.

\begin{tabular}{|c|c|c|c|c|c|c|c|}
\hline & \multicolumn{2}{|l|}{ Test } & \multicolumn{2}{|c|}{ ReTest } & \multicolumn{2}{|c|}{ Spearman's rho } & \multirow{2}{*}{$\begin{array}{l}\text { Wilcoxon } \\
\text { test } \\
P \text {-Value }\end{array}$} \\
\hline & Mean & $S D$ & Mean & $S D$ & $\overline{r_{\mathrm{s}}}$ & $P$-Value & \\
\hline Dot scanning & 3.50 & 2.84 & 3.00 & 2.34 & 0.18 & $0.58 n s$ & $0.27 n s$ \\
\hline Line scanning & 9.33 & 3.45 & 9.67 & 2.23 & 0.59 & $0.04 n s$ & $0.33 n s$ \\
\hline Texture discrimination & 9.17 & 1.99 & 9.33 & 1.97 & 0.37 & $0.23 n s$ & $0.39 n s$ \\
\hline Shape discrimination & 7.00 & 2.89 & 8.17 & 2.62 & 0.72 & $0.008 n s$ & $0.04 n s$ \\
\hline Size discrimination & 6.33 & 3.17 & 5.50 & 3.53 & 0.92 & $0.0001 *$ & $0.05 n s$ \\
\hline Spatial orientation & 8.67 & 2.99 & 9.83 & 1.99 & 0.73 & $0.006 n s$ & $0.04 n s$ \\
\hline Spatial location & 8.67 & 3.65 & 9.33 & 3.65 & 0.62 & $0.029 n s$ & $0.25 n s$ \\
\hline Dot span & 5.50 & 3.80 & 5.92 & 3.29 & 0.92 & $0.0001 *$ & $0.09 n s$ \\
\hline Shape span & 6.25 & 3.05 & 6.58 & 3.18 & 0.91 & $0.0001 *$ & $0.25 n s$ \\
\hline Picture identification & 6.38 & 2.13 & 7.25 & 3.19 & 0.72 & $0.008 n s$ & $0.12 n s$ \\
\hline Picture completion & 6.31 & 3.72 & 7.44 & 3.28 & 0.89 & $0.0001 *$ & $0.02 n s$ \\
\hline All tests & 77.10 & 23.51 & 82.02 & 24.02 & 0.93 & $0.0001 *$ & $0.02 n s$ \\
\hline
\end{tabular}

Note. Owing to multiple comparisons $(n=12)$, the alpha level was ajusted to 0.004 using the Bonferroni method. 
Table 4. Partial correlation coefficients (controlling for age) between scores on the 2D-Haptic test battery and scores on the B101.

\begin{tabular}{lll}
\hline & \multicolumn{2}{l}{ B101 score } \\
\cline { 2 - 3 } Dot scanning score & 0.24 & $p=0.104 \mathrm{~ns}$ \\
Line scanning score & 0.34 & $p=0.021 \mathrm{~ns}$ \\
Texture discrimination score & 0.16 & $p=0.278 \mathrm{~ns}$ \\
Shape discrimination score & 0.39 & $p=0.008 \mathrm{~ns}$ \\
Size discrimination score & -0.06 & $p=0.693 \mathrm{~ns}$ \\
Spatial orientation score & 0.34 & $p=0.020 \mathrm{~ns}$ \\
Spatial location score & 0.32 & $p=0.030 \mathrm{~ns}$ \\
Dot span score & 0.49 & $p=0.001 *$ \\
Shape span score & 0.31 & $p=0.036 \mathrm{~ns}$ \\
Picture identification score & 0.33 & $p=0.025 \mathrm{~ns}$ \\
Picture completion score & 0.44 & $p=0.001 *$ \\
Haptic composite score & 0.51 & $p=0.000 *$ \\
\hline
\end{tabular}


Table 5. Partial correlation coefficients (controlling for age) between scores on the 2D-Haptic test battery and raw scores on the WISC verbal subscale.

\begin{tabular}{|c|c|c|c|c|c|c|}
\hline \multirow[b]{2}{*}{ Dot scanning score } & \multicolumn{2}{|c|}{ Similarities score } & \multirow{2}{*}{$\begin{array}{l}\text { Vocabulary score } \\
0.37 p=0.003 \mathrm{~ns}\end{array}$} & Comprehension score & \multicolumn{2}{|c|}{ Verbal WISC score } \\
\hline & 0.29 & $p=0.023 n s$ & & $0.36 p=0.004 n s$ & 0.39 & $p=0.002 n s$ \\
\hline Line scanning score & 0.27 & $p=0.038 n s$ & $0.16 p=0.209 \mathrm{~ns}$ & $0.16 p=0.211 n s$ & 0.22 & $p=0.082 n s$ \\
\hline Texture discrimination score & 0.07 & $p=0.568 n s$ & $0.16 p=0.204 \mathrm{~ns}$ & $0.001 p=0.991 n s$ & 0.10 & $p=0.424 n s$ \\
\hline Shape discrimination score & 0.19 & $p=0.145 n s$ & $0.35 p=0.006 \mathrm{~ns}$ & $0.25 p=0.051 n s$ & 0.31 & $p=0.016 n s$ \\
\hline Size discrimination score & 0.03 & $p=0.813 n s$ & $0.05 p=0.686 \mathrm{~ns}$ & $-0.01 p=0.922 n s$ & 0.03 & $p=0.808 n s$ \\
\hline Spatial orientation score & 0.32 & $p=0.013 n s$ & $0.20 p=0.128 \mathrm{~ns}$ & $0.31 p=0.015 n s$ & 0.30 & $p=0.017 n s$ \\
\hline Spatial location score & 0.08 & $p=0.533 n s$ & $0.10 p=0.418 \mathrm{~ns}$ & $0.05 p=0.707 n s$ & 0.09 & $p=0.471 n s$ \\
\hline Dot span score & 0.41 & $p=0.001 *$ & $0.32 p=0.012 \mathrm{~ns}$ & $p=0.002 n s$ & 0.42 & $p=0.001 *$ \\
\hline Shape span score & 0.36 & $p=0.004 n s$ & $0.10 p=0.437 \mathrm{~ns}$ & $p=0.117 n s$ & 0.24 & $p=0.059 \mathrm{~ns}$ \\
\hline Picture identification score & 0.31 & $p=0.015 n s$ & $0.27 p=0.035 \mathrm{~ns}$ & $0.27 p=0.037 n s$ & 0.32 & $p=0.011 n s$ \\
\hline Picture completion score & 0.36 & $p=0.005 n s$ & $0.38 p=0.003 \mathrm{~ns}$ & $0.42 p=0.001 *$ & 0.44 & $p=0.000 *$ \\
\hline Haptic composite score & 0.40 & $p=0.001 *$ & $0.37 p=0.003 \mathrm{~ns}$ & $0.36 p=0.004 n s$ & 0.43 & $p=0.000 *$ \\
\hline
\end{tabular}

Note. Owing to multiple comparisons $(n=48)$, the alpha level was ajusted to 0.001 using the Bonferroni method. 
Table 6. Descriptive statistics and factor loadings from the exploratory factor analysis.

\begin{tabular}{llllll}
\hline & Mean & $S D$ & Factor 1 & Factor 2 & Factor 3 \\
\hline Test 1-Dot scanning & 4.59 & 3.67 & 0.06 & $\mathbf{0 . 9 0}$ & 0.17 \\
Test 2-Line scanning & 8.09 & 3.63 & 0.28 & $\mathbf{0 . 7 0}$ & 0.25 \\
Test 3-Texture discrimination & 7.64 & 3.08 & $\mathbf{0 . 7 6}$ & 0.02 & 0.20 \\
Test 4-Shape discrimination & 5.72 & 3.41 & $\mathbf{0 . 6 7}$ & 0.29 & 0.38 \\
Test 5-Size discrimination & 6.17 & 3.18 & $\mathbf{0 . 6 1}$ & 0.36 & 0.06 \\
Test 6-Spatial orientation & 8.41 & 3.00 & $\mathbf{0 . 6 8}$ & 0.19 & 0.30 \\
Test 7-Spatial location & 8.28 & 3.25 & $\mathbf{0 . 7 7}$ & 0.06 & 0.27 \\
Test 8-Dot span & 5.49 & 3.69 & $\mathbf{0 . 6 1}$ & 0.35 & 0.50 \\
Test 9-Shape span & 6.26 & 3.24 & $\mathbf{0 . 6 0}$ & 0.34 & 0.52 \\
Test 10-Picture identification & 5.98 & 2.97 & 0.16 & 0.10 & $\mathbf{0 . 9 1}$ \\
Test 11-Picture completion & 6.13 & 3.67 & 0.34 & 0.29 & $\mathbf{0 . 7 8}$ \\
\hline
\end{tabular}

Note. The criterion for loading was $>0.60$. 
Table 7. Summary of $p$ values for the main and interaction effects of age and vision for each dependent variable.

Partial eta squared is provided in brackets for significant effects.

\begin{tabular}{llll}
\hline Dependent variable & Vision effect & Age effect & Age x Vision effect \\
\hline Composite haptic score & $0.7431 n s$ & $0.0000 *(0.65)$ & $0.1149 n s$ \\
Dot scanning score & $0.1618 n s$ & $0.0000 *(0.21)$ & $0.0181 n s$ \\
Line scanning score & $0.0940 n s$ & $0.0000 *(0.28)$ & $0.0092 n s$ \\
Texture discrimination score & $0.0063 n s$ & $0.0000 *(0.27)$ & $0.7386 n s$ \\
Shape discrimination score & $0.5318 n s$ & $0.0000 *(0.39)$ & $0.2408 n s$ \\
Size discrimination score & $0.6927 n s$ & $0.0000 *(0.26)$ & $0.8576 n s$ \\
Spatial orientation score & $0.1701 n s$ & $0.0000 *(0.40)$ & $0.5563 n s$ \\
Spatial location score & $0.4630 n s$ & $0.0000 *(0.42)$ & $0.5757 n s$ \\
Dot span score & $0.3410 n s$ & $0.0000 *(0.60)$ & $0.9388 n s$ \\
Shape span score & $0.8271 n s$ & $0.0000 *(0.55)$ & $0.8214 n s$ \\
Picture identification score & $0.6627 n s$ & $0.0000 *(0.30)$ & $0.1432 n s$ \\
Picture completion score & $0.2886 n s$ & $0.0000 *(0.50)$ & $0.0061 n s$ \\
\hline
\end{tabular}

Note. Owing to multiple comparisons $(n=12)$, we adjusted the alpha level to 0.004 using the Bonferroni correction. 
Table 8. Mean scores on the 2D-Haptic test battery for low vision, legally blind, and totally blind participants. Comparison between mean values using ANCOVAs, with visual status (3) as a between-participants factor, and age in months as a covariate.

\begin{tabular}{|c|c|c|c|c|c|c|c|}
\hline & \multicolumn{2}{|c|}{ Low vision $(n=53)$} & \multicolumn{2}{|c|}{ Legally blind $(n=6)$} & \multicolumn{2}{|c|}{ Totally blind $(n=10)$} & \multirow[b]{2}{*}{$P$-Value } \\
\hline & Mean & $S E ;$ Min-Max & Mean & $S E ;$ Min-Max & Mean & $S E$; Min-Max & \\
\hline Composite haptic score & 70.99 & $2.96 ; 17.5-121.5$ & 80.86 & $8.66 ; 19.25-102.5$ & 73.79 & $7.36 ; 62-128.5$ & $0.55 n s$ \\
\hline Dot scanning score & 3.89 & $0.48 ; 0-12$ & 3.52 & $1.41 ; 0-8$ & 5.88 & $1.20 ; 0-12$ & $0.30 n s$ \\
\hline Line scanning score & 7.42 & $0.50 ; 0-12$ & 7.92 & $1.45 ; 0-12$ & 7.51 & $1.24 ; 4-12$ & $0.95 n s$ \\
\hline Texture discrimination score & 7.95 & $0.39 ; 0-12$ & 9.14 & $1.13 ; 2-12$ & 9.36 & $0.96 ; 8-12$ & $0.30 n s$ \\
\hline Shape discrimination score & 5.45 & $0.41 ; 0-12$ & 8.18 & $1.21 ; 4-10$ & 7.42 & $1.03 ; 6-12$ & $0.04 n s$ \\
\hline Size discrimination score & 6.26 & $0.41 ; 0-12$ & 6.85 & $1.20 ; 2-10$ & 5.92 & $1.02 ; 4-12$ & $0.84 n s$ \\
\hline Spatial orientation score & 8.36 & $0.38 ; 2-12$ & 7.89 & $1.12 ; 2-12$ & 6.57 & $0.96 ; 4-12$ & $0.24 n s$ \\
\hline Spatial location score & 8.24 & $0.40 ; 0-12$ & 8.87 & $1.16 ; 2-12$ & 8.79 & $0.99 ; 8-12$ & $0.80 n s$ \\
\hline Dot span score & 5.02 & $0.39 ; 0-12$ & 6.13 & $1.15 ; 0-12$ & 5.93 & $0.98 ; 2-12$ & $0.51 n s$ \\
\hline Shape span score & 6.05 & $0.37 ; 1-12$ & 7.74 & $1.09 ; 3-12$ & 6.67 & $0.93 ; 3-12$ & $0.32 n s$ \\
\hline Picture identification score & 6.40 & $0.38 ; 1.5-12$ & 6.68 & $1.12 ; 1.5-10.5$ & 4.97 & $0.95 ; 0-10.5$ & $0.37 n s$ \\
\hline Picture completion score & 5.94 & $0.44 ; 0-12$ & 7.94 & $1.29 ; 0.75-10.5$ & 4.78 & $1.10 ; 0-12$ & $0.19 n s$ \\
\hline
\end{tabular}

Note. Owing to multiple comparisons $(n=12)$, we adjusted the alpha level to 0.004 using the Bonferroni correction. $S E=$ standard error. MinMax $=$ minimum-maximum value. 
Table 9. Mean scores on the 2D-Haptic test battery of visually impaired participants with and without associated disorders. Comparison between mean values using ANCOVAs with associated disorder (2) as a between-participants factor, and age in months as a covariate.

\begin{tabular}{|c|c|c|c|c|c|}
\hline & \multicolumn{2}{|c|}{ No associated disorder $(n=43)$} & \multicolumn{2}{|c|}{ Associated disorder $(n=26)$} & \multirow[b]{2}{*}{$P$-Value } \\
\hline & Mean & $S E ;$ Min-Max & Mean & $S E ;$ Min-Max & \\
\hline Composite haptic score & 77.67 & $3.06 ; 19.25-128.5$ & 63.29 & $3.94 ; 17.5-102.5$ & $0.0055 n s$ \\
\hline Dot scanning score & 4.60 & $0.53 ; 0-12$ & 3.40 & $0.68 ; 0-12$ & $0.1668 n s$ \\
\hline Line scanning score & 8.11 & $0.53 ; 0-12$ & 6.43 & $0.68 ; 0-12$ & $0.0557 n s$ \\
\hline Texture discrimination score & 8.64 & $0.42 ; 0-12$ & 7.63 & $0.54 ; 0-12$ & $0.1505 n s$ \\
\hline Shape discrimination score & 6.40 & $0.47 ; 0-12$ & 5.27 & $0.60 ; 0-10$ & $0.1430 n s$ \\
\hline Size discrimination score & 6.46 & $0.44 ; 0-12$ & 5.92 & $0.57 ; 0-10$ & $0.4606 n s$ \\
\hline Spatial orientation score & 8.71 & $0.41 ; 2-12$ & 6.97 & $0.52 ; 2-12$ & $0.0109 n s$ \\
\hline Spatial location score & 8.86 & $0.42 ; 0-12$ & 7.57 & $0.54 ; 0-12$ & $0.0656 n s$ \\
\hline Dot span score & 6.01 & $0.40 ; 0-12$ & 3.98 & $0.52 ; 0-12$ & $0.0030 *$ \\
\hline Shape span score & 6.96 & $0.39 ; 1-12$ & 5.18 & $0.50 ; 2-12$ & $0.0065 n s$ \\
\hline Picture identification score & 6.47 & $0.42 ; 1.5-12$ & 5.80 & $0.54 ; 0-10.5$ & $0.3343 n s$ \\
\hline Picture completion score & 6.43 & $0.48 ; 0-12$ & 5.14 & $0.62 ; 0-10.5$ & $0.1061 n s$ \\
\hline
\end{tabular}

Note. Owing to multiple comparisons $(n=12)$, we adjusted the alpha level to 0.004 using the Bonferroni correction. SE: standard error. Min-Max $=$ minimum-maximum value. 
Table 10. Mean scores on the 2D-Haptic test battery of visually impaired participants who are Braille readers or who only read black script. Comparison between mean values using ANCOVAs with Braille reader (2: yes/no) as a between-participants factor, and age in months as a covariate.

\begin{tabular}{|c|c|c|c|c|c|}
\hline & \multicolumn{2}{|c|}{ Braille readers $(n=24)$} & \multicolumn{2}{|c|}{ Readers of black script $(n=45)$} & \multirow[b]{2}{*}{$P$-Value } \\
\hline & Mean & $S E$ & Mean & $S E$ & \\
\hline Composite haptic score & 79.31 & 4.46 & 68.48 & 3.17 & $0.0614 n s$ \\
\hline Dot scanning score & 4.91 & 0.74 & 3.74 & 0.53 & $0.2213 n s$ \\
\hline Line scanning score & 7.99 & 0.54 & 7.20 & 0.54 & $0.4115 n s$ \\
\hline Texture discrimination score & 9.54 & 0.57 & 7.57 & 0.40 & $0.0091 n s$ \\
\hline Shape discrimination score & 6.85 & 0.65 & 5.50 & 0.46 & $0.1100 n s$ \\
\hline Size discrimination score & 7.25 & 0.61 & 5.73 & 0.43 & $0.0555 n s$ \\
\hline Spatial orientation score & 7.73 & 0.60 & 8.23 & 0.42 & $0.5170 n s$ \\
\hline Spatial location score & 8.86 & 0.60 & 8.11 & 0.43 & $0.3376 n s$ \\
\hline Dot span score & 6.23 & 0.59 & 4.72 & 0.42 & $0.0500 n s$ \\
\hline Shape span score & 7.03 & 0.57 & 5.89 & 0.40 & $0.1203 n s$ \\
\hline Picture identification score & 6.38 & 0.59 & 6.12 & 0.42 & $0.7393 n s$ \\
\hline Picture completion score & 6.49 & 0.69 & 5.65 & 0.49 & $0.3408 n s$ \\
\hline
\end{tabular}

Note. Owing to multiple comparisons $(n=12)$, we adjusted the alpha level to 0.004 using the Bonferroni correction. $S E$ : standard error. 
Appendix A. Characteristics of the visually impaired participants $(n=69)$.

\begin{tabular}{|c|c|c|c|c|c|c|c|c|c|c|}
\hline \multirow[b]{2}{*}{$\begin{array}{l}\text { Parti } \\
\text { cipants }\end{array}$} & \multirow[b]{2}{*}{$\begin{array}{l}\text { Age } \\
\text { (yrs;mths) }\end{array}$} & \multirow[b]{2}{*}{ Sex } & \multirow[b]{2}{*}{$\begin{array}{l}\text { Handednes } \\
\mathrm{s}\end{array}$} & \multicolumn{2}{|c|}{ Visual acuity } & \multirow[b]{2}{*}{$\begin{array}{l}\text { Visual } \\
\text { status }\end{array}$} & \multirow{2}{*}{$\begin{array}{l}\text { Cause of } \\
\text { visual } \\
\text { deficiency }\end{array}$} & \multirow[b]{2}{*}{$\begin{array}{l}\text { Nature of visual } \\
\text { deficiency }\end{array}$} & \multirow{2}{*}{\multicolumn{2}{|c|}{$\begin{array}{l}\text { Reading } \\
\text { Associated disorder mode }\end{array}$}} \\
\hline & & & & $\begin{array}{l}\text { Right } \\
\text { eye }\end{array}$ & $\begin{array}{l}\text { Left } \\
\text { eye }\end{array}$ & & & & & \\
\hline & & & & & & legally & & glaucoma + optic nerve & & \\
\hline 1 & $5 ; 0$ & M & Left & 0.02 & 0.02 & blind & congenital & atrophy & none & Black script \\
\hline 2 & $5 ; 2$ & $\mathrm{~F}$ & Left & 0.02 & 0.1 & low vision cat 1 & congenital & coloboma & none & $\begin{array}{l}\text { Black script } \\
+ \text { Braille }\end{array}$ \\
\hline 3 & $5 ; 5$ & M & Right & 0.1 & 0.1 & low vision cat 1 & congenital & ocular toxoplasmosis & none & Black script \\
\hline 4 & $5 ; 6$ & $\mathrm{~F}$ & Right & 0.24 & 0.16 & low vision cat 1 & congenital & $\begin{array}{l}\text { Leber congenital } \\
\text { amaurosis }\end{array}$ & none & Black script \\
\hline & & & & & & & & ocular albinism + & language & \\
\hline 5 & $5 ; 7$ & M & Left & 0.1 & 0.1 & low vision cat 1 & congenital & amblyopia & impairment & Black script \\
\hline 6 & $5 ; 8$ & $\mathrm{~F}$ & Right & 0.2 & 0.13 & low vision cat 1 & congenital & cataract & none & Black script \\
\hline 7 & $5 ; 10$ & M & Right & 0.2 & 0.2 & low vision cat 1 & congenital & $\begin{array}{l}\text { Leber congenital } \\
\text { amaurosis }\end{array}$ & none & $\begin{array}{l}\text { Black script } \\
+ \text { Braille }\end{array}$ \\
\hline 8 & $5 ; 11$ & M & Right & 0.3 & 0,00 & low vision cat 1 & congenital & cataract + glaucoma & $\begin{array}{l}\text { language } \\
\text { impairment }\end{array}$ & Black script \\
\hline
\end{tabular}




\begin{tabular}{|c|c|c|c|c|c|c|c|c|c|c|}
\hline 9 & $6 ; 0$ & M & Left & 0.3 & 0.16 & low vision cat 1 & congenital & nystagmus & none & Black script \\
\hline 10 & $6 ; 1$ & $\mathrm{~F}$ & Right & $<0.1$ & $<0.1$ & low vision cat 2 & congenital & nystagmus & none & Black script \\
\hline 11 & $6 ; 3$ & M & Right & 0.07 & 0.09 & low vision cat 2 & congenital & achromatopsia & none & Black script \\
\hline 12 & $6 ; 5$ & $\mathrm{~F}$ & Right & 0.2 & 0.2 & low vision cat 1 & congenital & nystagmus & none & Black script \\
\hline 13 & $6 ; 7$ & M & Right & 0.19 & 0.2 & low vision cat 1 & congenital & ocular albinism & none & Black script \\
\hline 14 & $7 ; 5$ & M & Right & 0.15 & 0.15 & low vision cat 1 & congenital & ocular albinism & none & Black script \\
\hline 15 & $7 ; 5$ & M & Right & 0.1 & 0.1 & low vision cat 1 & congenital & coloboma & none & Black script \\
\hline 16 & $7 ; 5$ & M & Right & 0.05 & 0.18 & low vision cat 1 & congenital & retinopathy & epilepsy & Black script \\
\hline 17 & $7 ; 8$ & $\mathrm{~F}$ & Right & 0.15 & 0.3 & low vision cat 1 & congenital & hydrocephalia & mental retardation & Black script \\
\hline 18 & $7 ; 9$ & M & Right & 0.1 & 0.1 & low vision cat 1 & congenital & aniridia & none & Black script \\
\hline 19 & $7 ; 9$ & M & Right & 0.25 & 0.08 & low vision cat 1 & congenital & nystagmus & none & Black script \\
\hline 20 & $7 ; 10$ & $\mathrm{~F}$ & Right & 0.1 & 0.1 & low vision cat 1 & congenital & degeneration & none & Black script \\
\hline 21 & $8 ; 0$ & M & Right & 0.1 & 0.1 & low vision cat 1 & congenital & aniridia + hypermetropi & anone & Black script \\
\hline 22 & $8 ; 3$ & $\mathrm{~F}$ & Left & $<0.3$ & $<0.3$ & low vision cat 1 & congenital & aniridia & none & Black script \\
\hline 23 & $8 ; 5$ & M & Right & 0.12 & 0.1 & low vision cat 1 & congenital & ocular albinism & none & Black script \\
\hline 24 & $8 ; 11$ & M & Right & 0.00 & 0.00 & $\begin{array}{l}\text { totally } \\
\text { blind }\end{array}$ & congenital & unknown abnormality & autism & Braille \\
\hline 25 & $8 ; 11$ & M & Right & 0.21 & 0.23 & low vision cat 1 & congenital & nystagmus & none & Black script \\
\hline 26 & $8 ; 11$ & $\mathrm{~F}$ & Left & 0.5 & 0.3 & low vision cat 1 & congenital & amblyopia & $\begin{array}{l}\text { language } \\
\text { impairment }\end{array}$ & Black script \\
\hline
\end{tabular}




\begin{tabular}{|c|c|c|c|c|c|c|c|c|c|c|}
\hline 27 & $9 ; 1$ & M & Right & 0 & 0.04 & $\begin{array}{l}\text { legally } \\
\text { blind cat } 3\end{array}$ & congenital & $\begin{array}{l}\text { optic nerve } \\
\text { malformation }\end{array}$ & behavioral disorder & $\begin{array}{l}\text { Black script } \\
+ \text { Braille }\end{array}$ \\
\hline & & & & & & & & Leber congenital & & Black script \\
\hline 28 & $9 ; 2$ & $\mathrm{~F}$ & Right & 0.09 & 0.12 & low vision cat 1 & congenital & amaurosis & none & + Braille \\
\hline 29 & $9 ; 3$ & M & Right & 0.11 & 0.15 & low vision cat 1 & congenital & aniridia + glaucoma & $\begin{array}{l}\text { language } \\
\text { impairment }\end{array}$ & Black script \\
\hline 30 & $9 ; 11$ & M & Right & 0.24 & 0.21 & low vision cat 1 & congenital & high hypermetropia & none & Black script \\
\hline 31 & $10 ; 1$ & $\mathrm{~F}$ & Right & 0.32 & 0.16 & low vision cat 1 & congenital & ocular albinism & none & Black script \\
\hline 32 & $10 ; 2$ & M & Left & 0.06 & 0.1 & low vision cat 2 & congenital & $\begin{array}{l}\mathrm{X} \text { linked juvenile } \\
\text { retinoschisis }\end{array}$ & $\begin{array}{l}\text { language } \\
\text { impairment }\end{array}$ & $\begin{array}{l}\text { Black script } \\
+ \text { Braille }\end{array}$ \\
\hline 33 & $10 ; 2$ & $\mathrm{~F}$ & Right & 0.1 & 0.12 & low vision cat 1 & congenital & retinitis pigmentosa & none & Black script \\
\hline 34 & $10 ; 4$ & M & Right & 0.08 & 0.13 & low vision cat 1 & congenital & optic neuropathy & $\begin{array}{l}\text { language } \\
\text { impairment + } \\
\text { Fairbank disease }\end{array}$ & Black script \\
\hline 35 & $10 ; 4$ & M & Right & 0.06 & 0.05 & low vision cat 2 & congenital & optic atrophy & none & $\begin{array}{l}\text { Black script } \\
+ \text { Braille }\end{array}$ \\
\hline 36 & $10 ; 6$ & M & Right & 0.032 & 0 & $\begin{array}{l}\text { legally } \\
\text { blind }\end{array}$ & congenital & $\begin{array}{l}\text { neurofibromatosis type } \\
1\end{array}$ & none & Braille \\
\hline 37 & $10 ; 7$ & $\mathrm{M}$ & Left & 0.25 & 0 & low vision cat 1 & congenital & micro buds & $\begin{array}{l}\text { mental retardation }+ \\
\text { behavioral disorder }\end{array}$ & Black script \\
\hline 38 & $10 ; 7$ & & & 0.15 & 0.4 & low vision cat 1 & congenital & $\mathrm{X}$ linked juvenile & none & Black script \\
\hline
\end{tabular}


M Right

retinoschisis

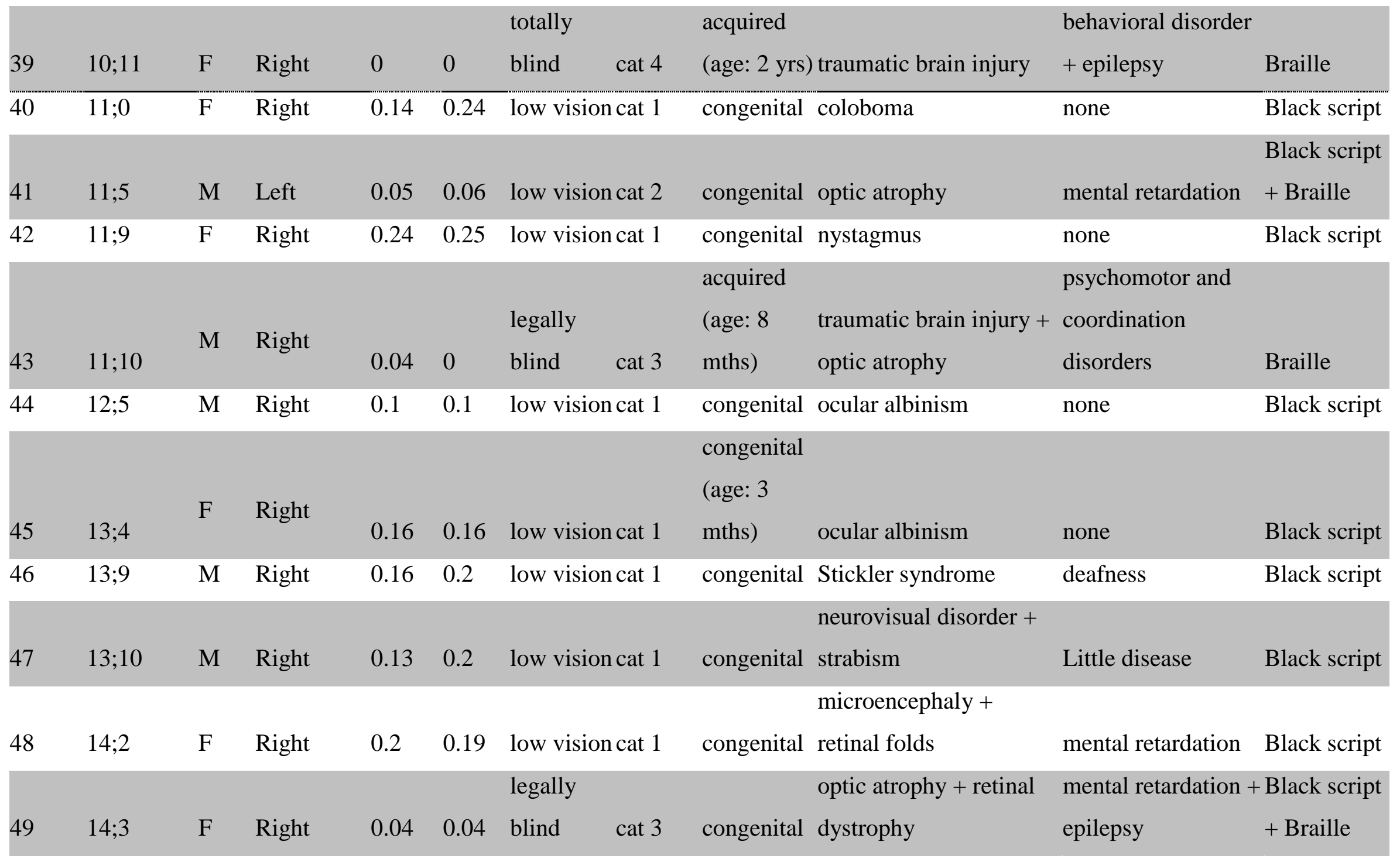




\begin{tabular}{|c|c|c|c|c|c|c|c|c|c|}
\hline 50 & $14 ; 6$ & $\mathrm{~F}$ & Right & 0.04 & 0 & $\begin{array}{l}\text { legally } \\
\text { blind }\end{array}$ & $\begin{array}{l}\text { acquired meningoencephalitis + } \\
\text { (age: } 9 \text { yrs) optic atrophy }\end{array}$ & $\begin{array}{l}\text { immunodeficiency } \\
+ \text { deafness }\end{array}$ & Braille \\
\hline 51 & $14 ; 6$ & $\mathrm{~F}$ & Left & 0.16 & 0.16 & low vision cat 1 & congenital achromatopsia & none & Black script \\
\hline 52 & $14 ; 8$ & M & Right & 0 & 0 & $\begin{array}{l}\text { totally } \\
\text { blind }\end{array}$ & congenital tumor & mental retardation & Braille \\
\hline 53 & $14 ; 11$ & M & Right & 0 & 0 & $\begin{array}{l}\text { totally } \\
\text { blind }\end{array}$ & Burkitt lymphoma & behavioral disorder & Braille \\
\hline & & & & & & & acquired & mental retardation + & Black script \\
\hline 54 & $15 ; 0$ & $\mathrm{~F}$ & Right & 0 & 0.1 & low vision cat 1 & (age: 3 yrs) uveitis & immunodeficiency & + Braille \\
\hline 55 & $15 ; 0$ & $\mathrm{~F}$ & Right & 0.3 & 0.3 & low vision cat 1 & congenital nystagmus & none & Black script \\
\hline 56 & $15 ; 2$ & M & Right & 0.11 & 0.05 & low vision cat 1 & $\begin{array}{l}\text { acquired } \\
\text { (age: } 6 \text { yrs) Stargardt disease }\end{array}$ & none & Black script \\
\hline 57 & $15 ; 4$ & M & Right & 0 & 0 & $\begin{array}{l}\text { totally } \\
\text { blind cat } 5\end{array}$ & $\begin{array}{ll} & \text { Leber congenital } \\
\text { congenital amaurosis }\end{array}$ & none & Braille \\
\hline 58 & $15 ; 4$ & M & Right & 0.08 & 0.09 & low vision cat 2 & congenital optic atrophy & none & Black script \\
\hline 59 & $15 ; 8$ & $\mathrm{~F}$ & Left & 0.0025 & 0.08 & low vision cat 2 & congenital optic atrophy & mental retardation & Black script \\
\hline 60 & $15 ; 10$ & M & Right & 0.18 & 0.16 & low vision cat 1 & $\begin{array}{r}\text { tapetoretinal } \\
\text { congenital degeneration }\end{array}$ & none & Black script \\
\hline 61 & $17 ; 7$ & M & Left & 0 & 0 & $\begin{array}{l}\text { totally } \\
\text { blind }\end{array}$ & congenital coloboma & mental retardation & Braille \\
\hline 62 & $18 ; 1$ & $\mathrm{~F}$ & Right & 0 & 0 & totally & congenital Leber congenital & none & Braille \\
\hline
\end{tabular}


blind

amaurosis

\begin{tabular}{|c|c|c|c|c|c|c|c|c|c|}
\hline \multirow[b]{2}{*}{63} & \multirow[b]{2}{*}{$18 ; 1$} & \multirow[b]{2}{*}{$\mathrm{F}$} & \multirow[b]{2}{*}{ Right } & \multirow[b]{2}{*}{0.4} & \multicolumn{5}{|c|}{ amblyopia + retinitis } \\
\hline & & & & & 0.05 & low vision cat 1 & congenital pigmentosa & mental retardation & Black script \\
\hline 64 & $18 ; 5$ & $\mathrm{~F}$ & Right & 0 & 0 & $\begin{array}{l}\text { totally } \\
\text { blind }\end{array}$ & congenital retrolental fibroplasia & none & Braille \\
\hline 65 & $18 ; 6$ & $\mathrm{~F}$ & Right & 0.04 & 0.07 & low vision cat 2 & congenital retinopathy & none & $\begin{array}{l}\text { Black script } \\
+ \text { Braille }\end{array}$ \\
\hline 66 & $21 ; 2$ & $\mathrm{~F}$ & Right & 0.08 & 0.08 & low vision cat 2 & congenital coloboma & $\begin{array}{l}\text { mental retardation - } \\
\text { epilepsy }\end{array}$ & Black script \\
\hline 67 & $22 ; 9$ & M & Right & 0 & 0 & $\begin{array}{l}\text { totally } \\
\text { blind }\end{array}$ & $\begin{array}{l}\text { acquired } \\
\text { (age: } 6 \text { yrs) Lyell syndrome }\end{array}$ & none & Braille \\
\hline 68 & $23 ; 9$ & M & Right & 0 & 0 & $\begin{array}{l}\text { totally } \\
\text { blind }\end{array}$ & congenital micro-ophtalmia & none & Braille \\
\hline 69 & $25 ; 4$ & $\mathrm{~F}$ & Right & $<0.3$ & $<0.3$ & low vision cat 1 & $\begin{array}{l}\text { acquired Stargardt disease }+ \\
\text { (age: } 9 \text { yrs) retinitis pigmentosa }\end{array}$ & none & $\begin{array}{l}\text { Black script } \\
+ \text { Braille }\end{array}$ \\
\hline
\end{tabular}

WHO $=$ World Health Organization.

Cat. 5: no light perception (total blindness); Cat. 4: light perception (total blindness); Cat. 3: visual acuity between 1/20 and 1/50 (legal blindness); Cat. 2: visual acuity between 1/10 and 1/20 (low vision); Cat. 1: visual acuity between 3/10 and 1/10 (low vision). 
Appendix B. Descriptive statistics for scores on the 2D-Haptic test battery in the case of normal and impaired vision for each age group.

\begin{tabular}{|c|c|c|c|c|c|c|c|}
\hline \multirow[b]{2}{*}{ Measure } & \multirow[b]{2}{*}{ Age group } & \multicolumn{2}{|c|}{ Normal vision } & \multicolumn{2}{|c|}{ Impaired vision } & \multicolumn{2}{|l|}{ Both } \\
\hline & & Mean & $S D$ & Mean & $S D$ & Mean & $S D$ \\
\hline \multirow{6}{*}{$\begin{array}{l}\text { Composite haptic score } \\
(0-132 \text { pts })\end{array}$} & $5-6$ yrs & 49.58 & 11.97 & 37.85 & 17.72 & 43.71 & 14.85 \\
\hline & $7-8 \mathrm{yrs}$ & 54.75 & 10.32 & 59.31 & 20.92 & 57.03 & 15.62 \\
\hline & $9-10 \mathrm{yrs}$ & 64.15 & 9.45 & 76.60 & 16.67 & 70.38 & 13.06 \\
\hline & $11-14 \mathrm{yrs}$ & 85.21 & 12.97 & 78.88 & 25.06 & 82.05 & 19.02 \\
\hline & $15-18$ yrs & 99.83 & 7.68 & 95.71 & 21.71 & 97.77 & 14.70 \\
\hline & $\begin{array}{l}\text { Young } \\
\text { adults }\end{array}$ & 115.00 & 6.06 & 114.19 & 12.90 & 114.59 & 9.48 \\
\hline \multirow{6}{*}{$\begin{array}{l}\text { Dot scanning score } \\
(0-12 \text { pts })\end{array}$} & $5-6 \mathrm{yrs}$ & 5.69 & 2.14 & 0.62 & 1.26 & 3.15 & 1.70 \\
\hline & $7-8$ yrs & 4.15 & 2.76 & 4.62 & 3.40 & 4.38 & 3.08 \\
\hline & $9-10$ yrs & 3.23 & 2.52 & 3.38 & 2.50 & 3.31 & 2.51 \\
\hline & $11-14$ yrs & 3.85 & 3.51 & 4.46 & 3.84 & 4.15 & 3.68 \\
\hline & $15-18$ yrs & 7.08 & 3.88 & 6.31 & 4.82 & 6.69 & 4.35 \\
\hline & $\begin{array}{l}\text { Young } \\
\text { adults }\end{array}$ & 9.00 & 2.00 & 8.50 & 4.43 & 8.75 & 3.22 \\
\hline \multirow{6}{*}{$\begin{array}{l}\text { Line scanning score } \\
(0-12 \text { pts })\end{array}$} & $5-6 \mathrm{yrs}$ & 8.46 & 2.33 & 3.23 & 3.32 & 5.85 & 2.83 \\
\hline & $7-8$ yrs & 6.46 & 3.48 & 7.38 & 3.59 & 6.92 & 3.54 \\
\hline & $9-10$ yrs & 8.46 & 2.60 & 7.54 & 3.28 & 8.00 & 2.94 \\
\hline & $11-14 \mathrm{yrs}$ & 8.15 & 3.11 & 7.54 & 4.01 & 7.85 & 3.56 \\
\hline & $15-18$ yrs & 11.23 & 1.30 & 10.31 & 3.04 & 10.77 & 2.17 \\
\hline & $\begin{array}{l}\text { Young } \\
\text { adults }\end{array}$ & 11.00 & 2.00 & 12.00 & 0.00 & 11.50 & 1.00 \\
\hline \multirow{6}{*}{$\begin{array}{l}\text { Texture discrimination score } \\
(0-12 \text { pts })\end{array}$} & $5-6 \mathrm{yrs}$ & 4.62 & 3.20 & 5.69 & 3.25 & 5.15 & 3.23 \\
\hline & $7-8$ yrs & 6.31 & 1.97 & 7.23 & 3.22 & 6.77 & 2.60 \\
\hline & $9-10 \mathrm{yrs}$ & 6.92 & 2.53 & 9.38 & 1.89 & 8.15 & 2.21 \\
\hline & $11-14$ yrs & 7.69 & 3.04 & 8.00 & 2.83 & 7.85 & 2.94 \\
\hline & $15-18$ yrs & 8.92 & 2.66 & 10.00 & 2.16 & 9.46 & 2.41 \\
\hline & Young & 9.00 & 1.15 & 11.50 & 1.00 & 10.25 & 1.08 \\
\hline
\end{tabular}




$\begin{array}{llllllll} & \text { adults } & & & & & \\ \text { Shape discrimination score } & 5-6 \text { yrs } & 2.92 & 2.78 & 3.69 & 2.43 & 3.31 & 2.61 \\ \text { (0-12 pts) } & 7-8 \text { yrs } & 3.54 & 2.33 & 3.85 & 3.41 & 3.69 & 2.87 \\ & 9-10 \text { yrs } & 4.31 & 1.97 & 6.92 & 3.12 & 5.62 & 2.55 \\ & 11-14 \text { yrs } & 7.38 & 2.63 & 6.31 & 3.82 & 6.85 & 3.23 \\ & 15-18 \text { yrs } & 7.38 & 2.22 & 7.69 & 2.43 & 7.54 & 2.33 \\ & \text { Young } & 11.50 & 1.00 & 10.50 & 1.91 & 11.00 & 1.46 \\ & \text { adults } & & & & & & \\ \text { Size discrimination score } & 5-6 \text { yrs } & 4.62 & 2.36 & 4.00 & 3.06 & 4.31 & 2.71 \\ \text { (0-12 pts) } & 7-8 \text { yrs } & 4.77 & 2.52 & 5.38 & 2.75 & 5.08 & 2.64 \\ & 9-10 \text { yrs } & 4.77 & 3.11 & 6.00 & 3.16 & 5.38 & 3.14 \\ & 11-14 \text { yrs } & 7.69 & 2.14 & 7.23 & 3.42 & 7.46 & 2.78 \\ & 15-18 \text { yrs } & 7.38 & 3.50 & 7.38 & 2.36 & 7.38 & 2.93 \\ \text { Spatial orientation score } & \text { Young } & 10.00 & 2.31 & 10.50 & 1.91 & 10.25 & 2.11 \\ \text { (0-12 pts) } & \text { adults } & & & & & & \\ & 5-6 \text { yrs } & 5.23 & 1.92 & 5.08 & 2.40 & 5.15 & 2.16 \\ & 7-8 \text { yrs } & 8.00 & 2.16 & 6.77 & 3.22 & 7.38 & 2.69 \\ & 9-10 \text { yrs } & 8.62 & 2.50 & 9.08 & 1.93 & 8.85 & 2.22 \\ & 11-14 \text { yrs } & 10.62 & 1.50 & 8.77 & 3.52 & 9.69 & 2.51 \\ \text { Dot span score } & 15-18 \text { yrs } & 10.62 & 1.71 & 9.69 & 2.56 & 10.15 & 2.14 \\ \text { Young } & 11.00 & 1.15 & 11.00 & 1.15 & 11.00 & 1.15 \\ \text { (0-12 pts) } & \text { adults } & & & & & & 3.32 \\ & 5-6 \text { yrs } & 4.46 & 2.85 & 5.23 & 3.79 & 4.85 & 3.06 \\ & 7-8 \text { yrs } & 6.31 & 2.69 & 7.23 & 3.42 & 6.77 & 2.23 \\ & 9-10 \text { yrs } & 8.62 & 2.36 & 9.23 & 2.09 & 8.92 & 2.25 \\ & 11-14 \text { yrs } & 10.00 & 1.83 & 8.92 & 2.66 & 9.46 & 1.65 \\ & 15-18 \text { yrs } & 10.92 & 1.32 & 10.31 & 1.97 & 10.62 & 1.32 \\ & \text { Young } & 10.00 & 1.63 & 11.50 & 1.00 & 10.75 & 1.28\end{array}$




\begin{tabular}{|c|c|c|c|c|c|c|c|}
\hline \multirow[t]{5}{*}{$(0-12 \mathrm{pts})$} & $7-8$ yrs & 2.38 & 1.50 & 2.69 & 1.65 & 2.54 & 1.58 \\
\hline & $9-10$ yrs & 5.08 & 1.71 & 4.69 & 2.53 & 4.88 & 2.12 \\
\hline & $11-14 \mathrm{yrs}$ & 7.62 & 3.04 & 6.62 & 3.43 & 7.12 & 3.24 \\
\hline & $15-18$ yrs & 9.46 & 2.33 & 8.69 & 3.86 & 9.08 & 3.10 \\
\hline & $\begin{array}{l}\text { Young } \\
\text { adults }\end{array}$ & 10.50 & 1.73 & 10.50 & 3.00 & 10.50 & 2.37 \\
\hline \multirow{6}{*}{$\begin{array}{l}\text { Shape span score } \\
(0-12 \text { pts })\end{array}$} & $5-6 \mathrm{yrs}$ & 2.69 & 0.75 & 3.08 & 1.55 & 2.88 & 1.15 \\
\hline & $7-8$ yrs & 4.00 & 1.83 & 4.69 & 2.69 & 4.35 & 2.26 \\
\hline & $9-10 \mathrm{yrs}$ & 5.85 & 2.03 & 6.23 & 2.45 & 6.04 & 2.24 \\
\hline & $11-14 \mathrm{yrs}$ & 7.85 & 1.86 & 7.77 & 3.19 & 7.81 & 2.53 \\
\hline & $15-18$ yrs & 9.23 & 2.01 & 8.54 & 3.36 & 8.88 & 2.69 \\
\hline & $\begin{array}{l}\text { Young } \\
\text { adults }\end{array}$ & 11.25 & 0.96 & 10.00 & 1.83 & 10.63 & 1.40 \\
\hline \multirow{6}{*}{$\begin{array}{l}\text { Picture identification score } \\
(0-12 \mathrm{pts})\end{array}$} & $5-6$ yrs & 3.81 & 2.42 & 3.35 & 2.05 & 3.58 & 2.24 \\
\hline & $7-8$ yrs & 4.85 & 2.54 & 5.88 & 2.97 & 5.37 & 2.76 \\
\hline & $9-10 \mathrm{yrs}$ & 4.50 & 2.29 & 7.15 & 2.82 & 5.83 & 2.56 \\
\hline & $11-14$ yrs & 6.23 & 2.80 & 6.23 & 2.44 & 6.23 & 2.62 \\
\hline & $15-18$ yrs & 7.85 & 1.85 & 7.73 & 2.93 & 7.79 & 2.39 \\
\hline & $\begin{array}{l}\text { Young } \\
\text { adults }\end{array}$ & 10.50 & 1.22 & 8.63 & 2.84 & 9.56 & 2.03 \\
\hline \multirow{6}{*}{$\begin{array}{l}\text { Picture completion score } \\
(0-12 \mathrm{pts})\end{array}$} & $5-6$ yrs & 4.38 & 2.58 & 1.96 & 2.36 & 3.17 & 2.47 \\
\hline & $7-8$ yrs & 3.98 & 1.69 & 3.58 & 2.51 & 3.78 & 2.10 \\
\hline & $9-10$ yrs & 3.81 & 2.46 & 6.98 & 3.07 & 5.39 & 2.77 \\
\hline & $11-14 \mathrm{yrs}$ & 8.13 & 1.98 & 7.04 & 3.66 & 7.59 & 2.82 \\
\hline & $15-18$ yrs & 9.75 & 1.37 & 9.06 & 3.36 & 9.40 & 2.37 \\
\hline & $\begin{array}{l}\text { Young } \\
\text { adults }\end{array}$ & 11.25 & 0.87 & 9.56 & 3.94 & 10.41 & 2.41 \\
\hline
\end{tabular}




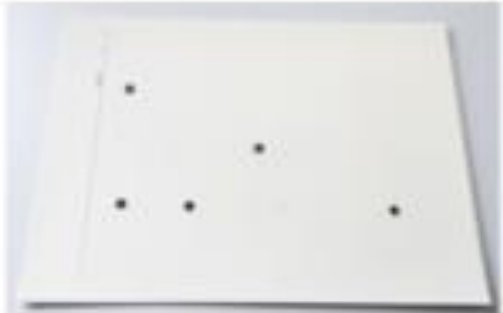

Dot Scanning

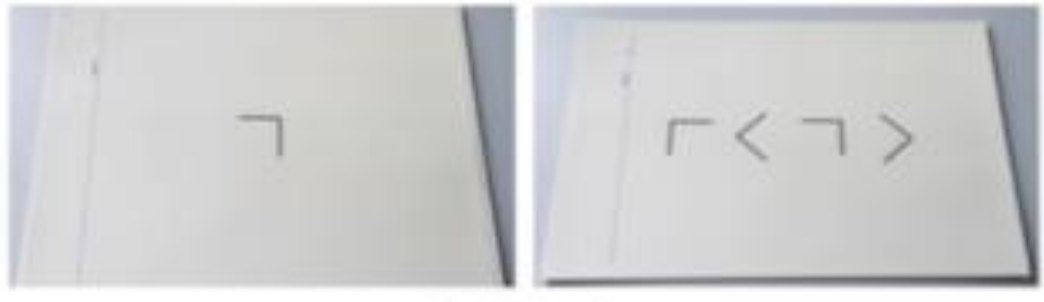

Spatial Onematation

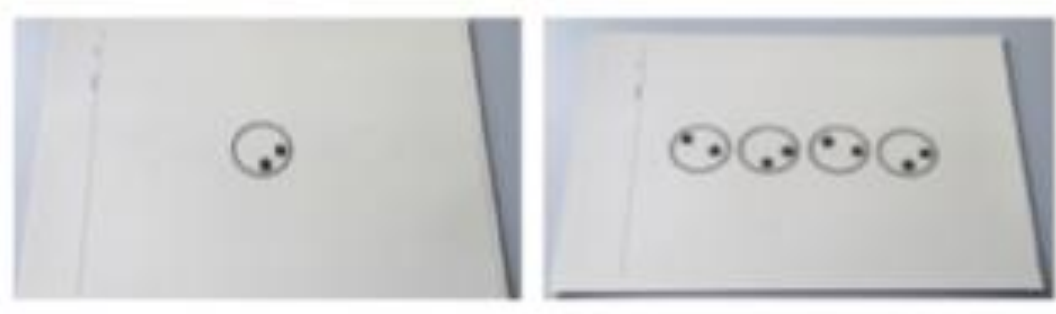

Spatial Location

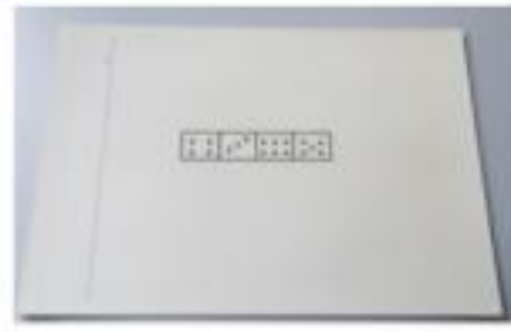

Dot Span

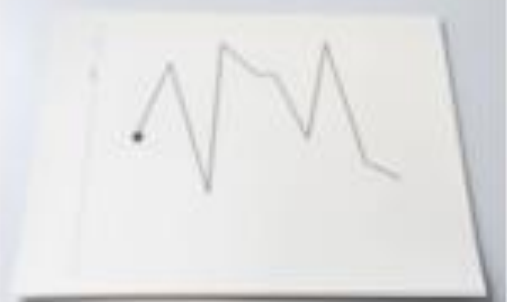

Line Scanning

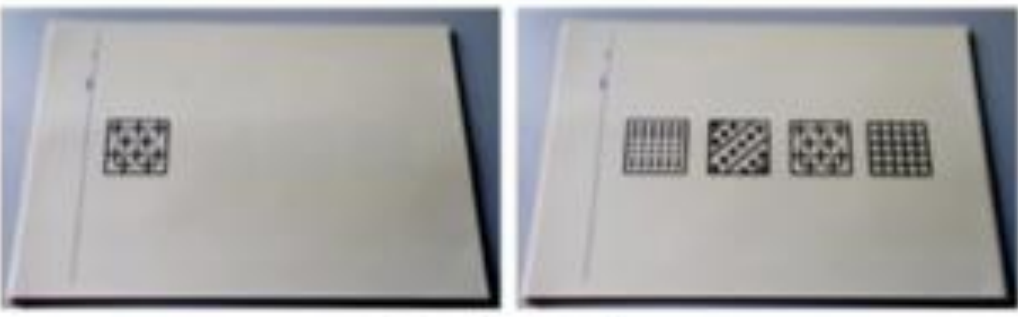

Texture Discrimination

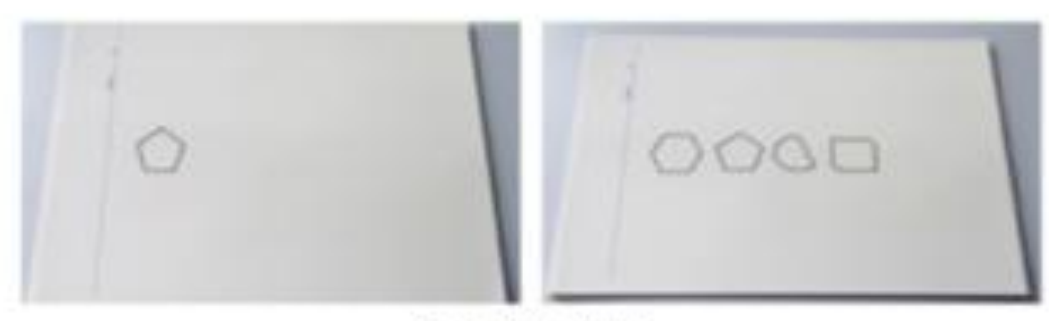

Shape Discrimination

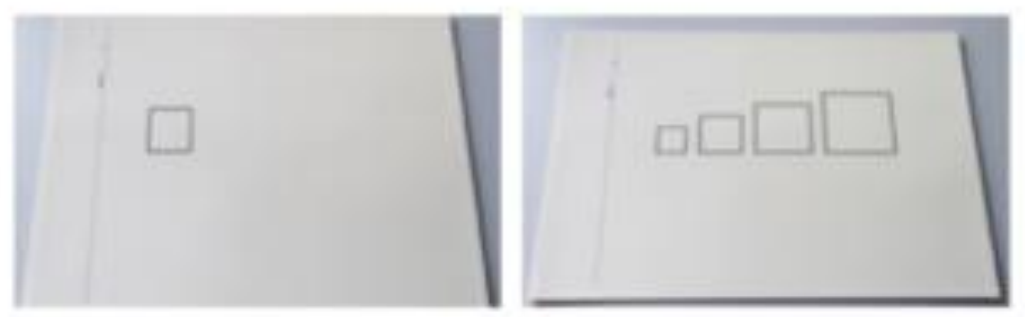

Skze Discriminatiog

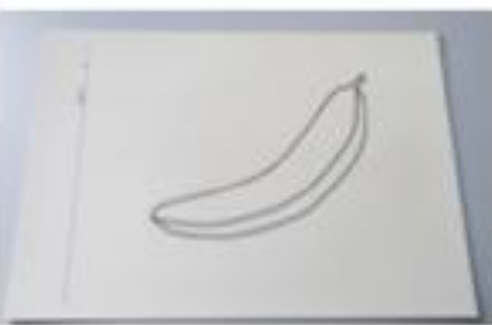

Picture Identification

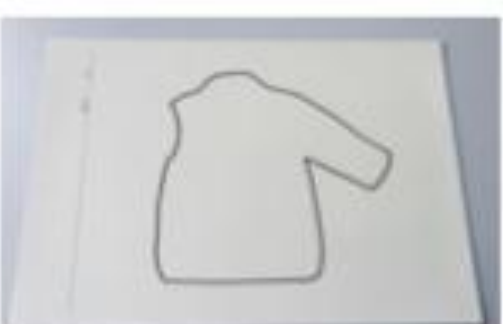

Picture Completiee 


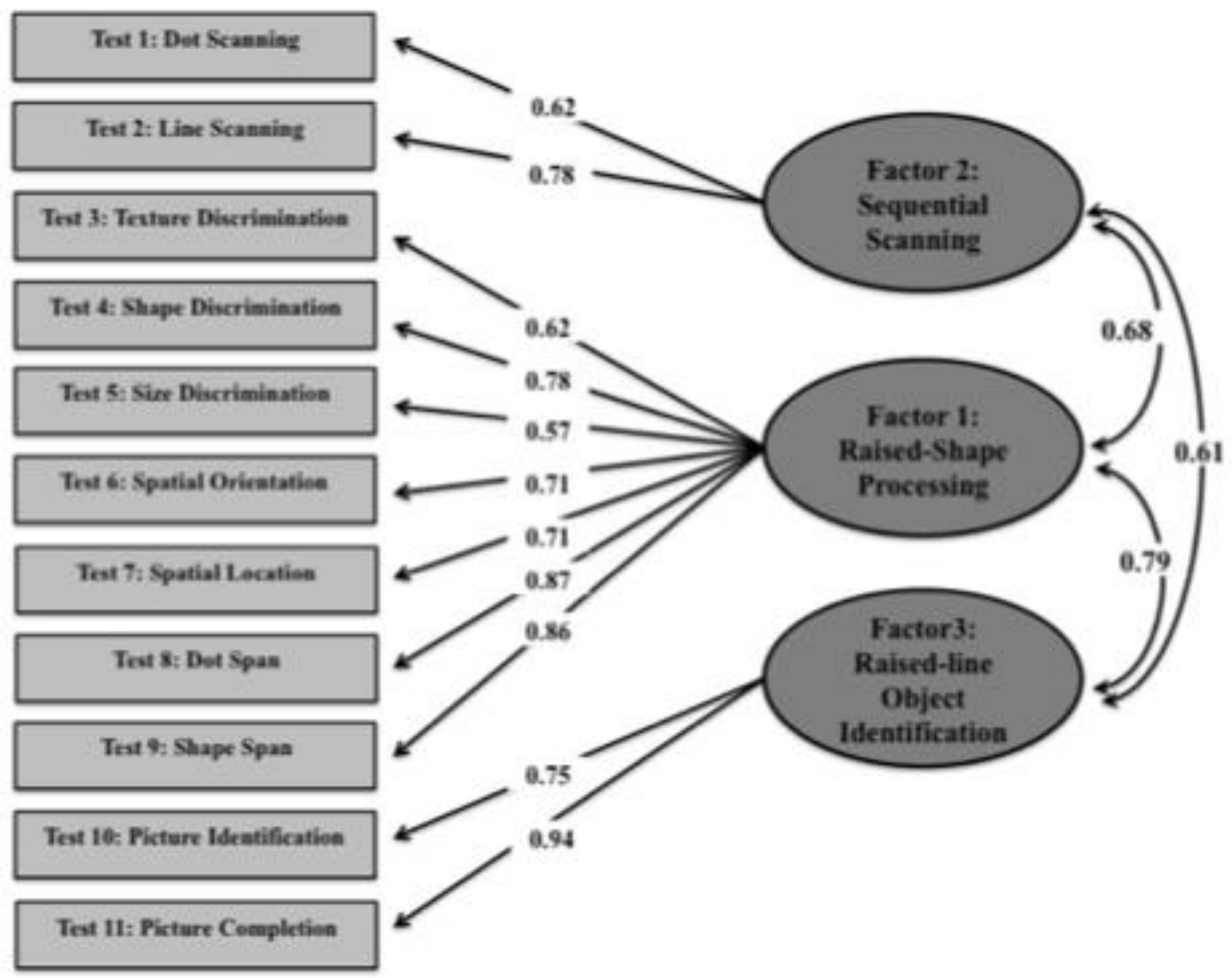

